\title{
Building of the Amsterdam-Saint Paul plateau: A 10 Myr history of a ridge-hot spot interaction and variations in the strength of the hot spot source
}

\author{
Marcia Maia, ${ }^{1,2}$ Ivo Pessanha, ${ }^{1,2,3}$ Esther Courrèges, ${ }^{1,4}$ Martin Patriat, ${ }^{4}$ Pascal Gente, ${ }^{1,2}$ \\ Christophe Hémond, ${ }^{1,2}$ Myriam Janin, ${ }^{1,2,5}$ Kevin Johnson, ${ }^{6}$ Walter Roest, ${ }^{4}$ \\ Jean-Yves Royer, ${ }^{1,2}$ and Judith Vatteville ${ }^{7}$ \\ Received 8 June 2010; revised 14 June 2011; accepted 29 June 2011; published 22 September 2011.
}

[1] The Amsterdam-Saint Paul plateau results from a $10 \mathrm{Myr}$ interaction between the South East Indian Ridge and the Amsterdam-Saint Paul hot spot. During this period of time, the structure of the plateau changed as a consequence of changes in both the ridge-hot spot relative distance and in the strength of the hot spot source. The joint analysis of gravity-derived crust thickness and bathymetry reveals that the plateau started to form at $\sim 10 \mathrm{Ma}$ by an increase of the crustal production at the ridge axis, due to the nearby hot spot. This phase, which lasted 3-4 Myr, corresponds to a period of a strong hot spot source, maybe due to a high temperature or material flux, and decreasing ridge-hot spot distance. A second phase, between $\sim 6$ and $\sim 3 \mathrm{Ma}$, corresponds to a decrease in the ridge crustal production. During this period, the hot spot center was close to the ridge axis and this reduced magmatic activity suggests a weak hot spot source. At $\sim 3 \mathrm{Ma}$, the ridge was located approximately above the hot spot center. An increase in the hot spot source strength then resulted in the building of the shallower part of the plateau. The variations of the melt production at the ridge axis through time resulted in variations in crustal thickness but also in changes in the ridge morphology. The two periods of increased melt production correspond to smooth ridge morphology, characterized by axial highs, while the intermediate period corresponds to a rougher, rift-valley morphology. These variations reveal changes in axial thermal structure due to higher melting production rates and temperatures.

Citation: Maia, M., et al. (2011), Building of the Amsterdam-Saint Paul plateau: A 10 Myr history of a ridge-hot spot interaction and variations in the strength of the hot spot source, J. Geophys. Res., 116, B09104, doi:10.1029/2010JB007768.

\section{Introduction}

[2] Mid-oceanic ridges interact with hot spots and as a consequence, the structure and composition of the oceanic crust and lithosphere are modified [e.g., Schilling, 1991; Ito et al., 2003]. Basalts are enriched in terms of incompatible elements and show a distinct isotopic signature, the oceanic crust created at the ridge axis is thicker than average while

\footnotetext{
${ }^{1}$ Université Européenne de Bretagne, Rennes, France.

${ }^{2}$ Laboratoire Domaines Océaniques, Institut Universitaire Europeen de la Mer, Université de Brest, CNRS, Plouzané, France.

${ }^{3}$ Now at LAGEMAR, Universidade Federal Fluminense, Niterói, Brazil.

${ }^{4}$ IFREMER, Département de Géosciences Marines, Centre de Brest, Plouzané, France.

${ }^{5}$ Now at Commissariat à l'Énergie Atomique, Gif-sur-Yvette, France.

${ }^{6}$ Department of Geology and Geophysics, School of Ocean and Earth Sciences and Technology, University of Hawaii at Manoa, Honolulu, Hawaii, USA.

${ }^{7}$ Laboratoire de Dynamique des Fluides Géologiques, Institut de Physique du Globe, Paris, France.
}

Copyright 2011 by the American Geophysical Union. 0148-0227/11/2010JB007768 the lithosphere is thinner and weaker due to the higher average mantle temperatures and to the thicker crust [e.g., Ito et al., 2003]. One of the most impressive consequences of ridge-hot spot interactions is the building of axial volcanic plateaus [e.g., Small, 1995; Gente et al., 2003]. Major plateaus, such as Iceland and the Azores, represent crustal thicknesses in excess of more that $20 \mathrm{~km}$ compared to an average $6 \mathrm{~km}$ oceanic crust, and their chemical composition reveal the existence of an enriched hot spot source, mixed with the depleted upper mantle [e.g., Schaefer et al., 2002; Sigmarsson and Steinthórsson, 2007]. The building processes of such plateaus are not yet fully understood. Numerical models suggest that large plateaus, such as Iceland, can be due to a thermal anomaly of 70 to $150^{\circ} \mathrm{C}$ beneath the ridge axis [Ito et al., 1996]. One important factor controlling plateau construction appears to be the relative motion and the distance between the accreting ridge and the hot spot [e.g., Gente et al., 2003]. When the ridge and the hot spot are close enough, the connection results in an increase of the melting regime at the axis, with a major building phase when the ridge is centered above the hot spot. Increasing ridge-hot spot distances result in a decrease of the axial melt production 


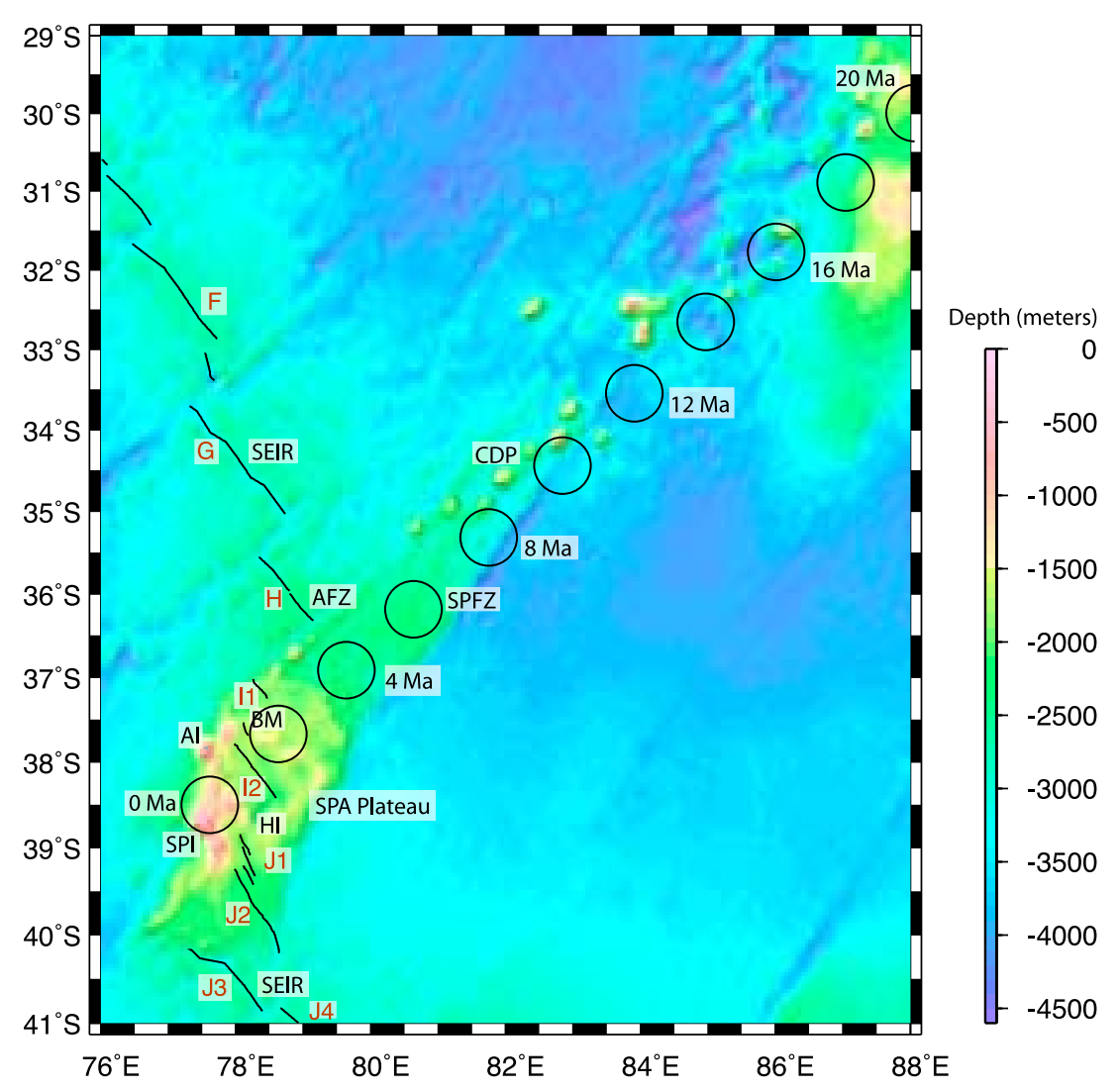

Figure 1. Merged multibeam and predicted bathymetry (from satellite altimetry of Smith and Sandwell [1997]) for the study area showing the main features of the ASP-SEIR system and the general geodynamic context. Multibeam bathymetry was collected during the 1996 Boomerang cruise [Scheirer et al., 2000] and the 2006 PLURIEL cruise. The SEIR axis, shown by the thin black lines, is taken from Scheirer et al. [2000] and Conder et al. [2000]. Open circles show the hypothetical location of the ASP hot spot for the last $20 \mathrm{Myr}$ at a $2 \mathrm{Myr}$ interval, assuming a present location between the islands of Amsterdam (AI) and St Paul (SPI) (see text for details). SEIR segments from F to J4 are named after Scheirer et al. [2000] (red labels). BM and HI stand for Boomerang and Hillegom transforms. CDP shows the emplacement of the volcanoes of the chain of the Dead Poets.

and of the crustal thickness, leading to the plateau breakup and finally to a return to a "normal" accreting regime [Gente et al., 2003]. There is evidence that temporal variations in the flux of the source of the hot spot, either thermal or material, may also play a major role in plateau evolution [Cannat et al., 1999; Allen et al., 2002; Maia et al., 2007a]. Off-axis magmatism also appears to be common in such contexts, increasing even more the thickness of the crust that was already formed at the ridge axis [e.g., Cannat et al., 1999; Conder et al., 2000].

[3] The ridge spreading rate is also an important parameter since it controls the axial crustal structure and morphology. Intermediate spreading ridges display a strong variability in terms of morphology and crustal structure [Cochran et al., 1997; Sempéré et al., 1997], and may correspond to a threshold in the lithosphere rheology, where small variations in the mantle temperature result in significant changes in the ridge characteristics [Chen and Lin, 2004]. At end-member spreading rates, either slow or fast, temperature or compositional variations in the mantle may have different effects. Slow spreading rates may favor the formation of volcanic plateaus at the ridge axis by contributing to focus the excess melt due to the hot spot, while at a fast rate, it is possible that more melt would be required to form an equivalent plateau. Ridge spreading rates thus probably control the axial expression of the thermo-chemical anomalies related to hot spots. The ridge absolute migration rate (relative velocity between the ridge and the hot spot) can also be an important factor. A fast migration rate, when the ridge is moving toward the hot spot, can result in the overriding plate dragging part of the hot spot material away from the ridge [Ribe and Delattre, 1998; Maia et al., 2000, 2001], thus reducing the amount of excess melting at the axis and reducing or delaying the possibility of plateau formation. A subsidiary question concerns the early phase of the interaction between the ridge and the hot spot. Studies of a fast ridge rapidly migrating toward a hot spot show that off-axis volcanoes may be present very close to the ridge axis [Maia et al., 2000, 2001]. The absence of other studies, covering different spreading rates or ridge migration rates, prevents a thorough understanding of the transition between the intraplate phase, characterized by the building of off-axis volcanoes, and the axial phase, when the hot spot influence at the ridge axis increases, with or without construction of a plateau.

[4] To address this problem, detailed data on the evolution of a plateau, from the early phases of building to the 


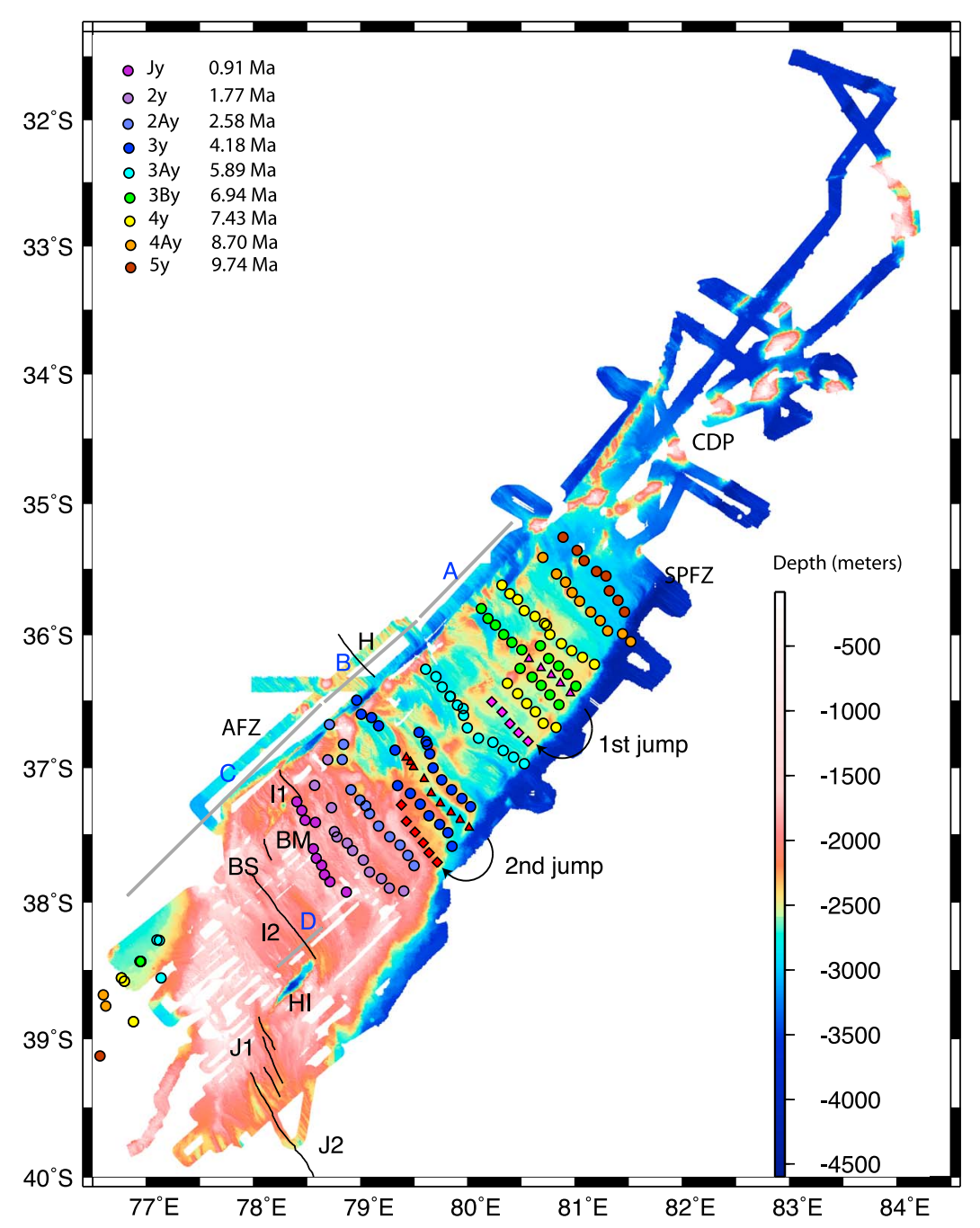

Figure 2. Multibeam bathymetry of the ASP-SEIR system. The identifications of the magnetic anomalies (color circles) are discussed in detail by E. Courrèges et al. (submitted manuscript, 2011). The two ridge jumps identified in the area are shown by the magenta and red colors, with triangles for the failed axis and diamonds for the corresponding new ridges. The sense of the jumps is shown by the black arrows. SEIR segments labeled as in Figure 1. AFZ, SPFZ stand for Amsterdam and St. Paul fracture zones, $\mathrm{HI}$ and BM stand for Hillegom and Boomerang transforms. CDP shows the emplacement of the volcanoes forming the chain of the Dead Poets. The gray lines with blue labels A, B, C and D mark the locations of the different magmatic and tectonic phases (see text for discussion).

final breakup, is essential. In September/October 2006, the PLURIEL cruise targeted the study of the Amsterdam-Saint Paul (ASP)-South East Indian Ridge (SEIR) system [Maia et al., 2007b, 2008]. This system consists of a volcanic plateau, presently in the early stages of breakup, and of an off-axis volcanic chain located on the Australian plate (Figure 1). During the cruise, we acquired a full multibeam coverage from the area near the ridge axis, partly surveyed by the previous Boomerang cruise in 1996 [Scheirer et al., 2000; Conder et al., 2000; Johnson et al., 2000] to the offaxis volcanoes, as well as magnetics and gravity (Figure 2). Forty dredge hauls were carried on and several successfully returned basalts. Here we focus on the analysis of the bathymetry and gravity data to show that the building of the ASP volcanic plateau is a complex process, involving ridge jumps and variations in the strength of the hot spot source. Detailed analysis of the kinematic evolution of the SEIR through $10 \mathrm{Myr}$ from the interpretation of the magnetic anomalies and of the geochronology of the volcanic edifices are presented in two companion papers [Janin et al., 2011; E. Courrèges et al., Evolution of ridge segmentation on the St-Paul-Amsterdam plateau from $10 \mathrm{Ma}$, in the context of ridge-hot spot interaction, submitted to Journal of Geophysical Research, 2011].

\section{Data Set and Methods}

[5] During the PLURIEL cruise, the bathymetry was acquired with a SeaFalcon II echo sounder at a rate of $10 \mathrm{~s}$. The data set was edited for spurious pings and filtered to reduce the noise level. After data cleaning, a bathymetric grid covering the whole surveyed area was interpolated at a $200 \mathrm{~m}$ horizontal resolution, integrating Seabeam 2000 data from the Boomerang cruise [Scheirer et al., 2000]. The 
spacing between the ship profiles was evaluated to insure a small overlap at the edges of the swaths. The high resolution bathymetry grid (Figure 2) was used in the structural analysis. A coarser grid with a $1 \mathrm{~km}$ horizontal resolution was used for the gravity calculations.

[6] A Geometrics proton precession magnetometer was used to acquire magnetic data along the profiles. The data was processed in a conventional way, removing the spurious spikes and correcting for the IGRF 2005. Detailed discussion on the identification and the interpretation of the magnetic anomalies is presented by E. Courrèges et al. (submitted manuscript, 2011). The magnetic anomalies were used to derive an age grid for the area, interpolated with a nearneighbor algorithm [Wessel and Smith, 1998] and including data from the global ages database [Müeller et al., 1997] outside of the study area. This grid was used for the calculation of a residual bathymetry and a residual Mantle Bouguer anomaly.

[7] Gravity data was acquired with a Lacoste Romberg AirSea gravity meter, with a 10 s sampling rate and processed in a conventional way to compute the free air anomaly (time lag correction, Eotvös effect, drift correction, low-pass filtering and removal of the GRS80). During processing, a problem with the stabilization of the platform at high sea states was detected. This problem introduced a long wavelength trend in a few profiles, or parts of profiles. The solution was to fit the long wavelength of satellite free air anomalies to the profiles in order to remove the anomalous trend. This technique allowed the recovering of all the cruise profiles. A data set was then built including the gravity profiles of the Boomerang cruise. After a crossover analysis and minimization, the RMS error is of $2.1 \mathrm{mGal}$, this high value being due to bad weather conditions during part of the PLURIEL cruise. The free air gravity grid (Figure 3a) was built by integrating the free air anomalies from other available ship profiles and from satellite data [Maia and ArkaniHamed, 2002]. Coherence analysis between the free air and the bathymetry grids reveals that the correlation coefficient drops rapidly for wavelengths shorter than $25-30 \mathrm{~km}$. Therefore, shorter wavelengths were filtered out of the data sets used for gravity modeling (Figure $3 b$ ).

[8] Gravity anomalies are currently used to assess the crustal pattern through the calculation of Mantle Bouguer anomalies (MBA) [Prince and Forsyth, 1988], computed by removing from the free air anomalies the effects of the topography and of a theoretical crust-mantle interface assuming a constant crustal thickness (Figure 3c). The following parameters were assumed in our model: 1030, 2800 and $3300 \mathrm{~kg} / \mathrm{m}^{3}$ for average seawater, crust and mantle densities and $6 \mathrm{~km}$ for the average thickness of the crust. Sediment thicknesses were estimated from several $3.5 \mathrm{kHz}$ sounder profiles and were neither extremely large nor highly variable for the area. Thicker values may be probably present between the islands of Amsterdam and St Paul, where volcanoclastic material mixed with carbonates was recovered in the dredges and locally near the taller volcanoes of the chain, due to mass waste. We estimate the contribution of the sediments to the gravity signal as being less than $5 \mathrm{mGal}$ at relatively high frequencies, since sediments accumulate in small, scattered pockets. The multilayer method [Maia and Arkani-Hamed, 2002] was used for the gravity calculations. In order to compute crustal thickness variations it is necessary to remove from the MBA the effect of lateral density variations related to the cooling of the lithosphere, that dominates the signal [Kuo and Forsyth, 1988]. This is also required because we intend to estimate temporal variations in the accretion pattern over $10 \mathrm{Myr}$ and therefore age effects must be removed from both the bathymetry and the gravity. The unstable geometry of the SEIR at the ASP plateau [Conder et al., 2000; E Courrèges et al., submitted manuscript, 2011] precludes the calculation of a flow model from simplified ridge geometry, as is usually done [Morgan and Forsyth, 1988]. We chose to compute mantle effects from the age grid derived from the identification of the magnetic anomalies that account for the complex time evolution of the spreading geometry [Rommevaux et al., 1994]. The depth of a density interface following the base of the lithosphere is calculated from the age grid following a half-space model and a density contrast of $-60 \mathrm{~kg} / \mathrm{m}^{3}$ between the lithosphere and the asthenosphere is then assumed (Figure 3d). Age identifications were also used to compute a subsidence grid that was removed from the bathymetry to obtain residual depths (Figure 4). The subsidence is computed using the law proposed by Parsons and Sclater [1977] with a value of $342 \mathrm{~m} / \mathrm{Myr}$ for the subsidence coefficient [Stein and Stein, 1992] and an average ridge axial depth of $2600 \mathrm{~m}$, [Ito and Lin, 1995].

[9] The residual Mantle Bouguer anomaly (RMBA) obtained after the removal of the cooling effect can be interpreted in terms of variations in crustal thickness and/or in crustal or mantle densities. Usually, as a first approximation, density in both crust and mantle is considered to be constant and the RMBA is inverted for variations in the crustal thickness [Kuo and Forsyth, 1988]. Seismic studies along mid-oceanic ridge axes [e.g., Canales et al., 2000] show that this approximation is generally valid. However, in areas under the influence of hot spots, mantle densities are expected to vary, thus contributing to the long wavelengths of the RMBA. Different studies estimate this contribution to be of the order of 20 to $25 \%$ of the signal for large hot spots, such as Galapagos or the Azores [e.g., Canales et al., 2002; Maia et al., 2007a]. Scheirer et al. [2000], however, suggest that the mantle effect of the ASP hot spot on the gravity signal is minor, since the long wavelength effect of the hot spot along the SEIR axis is small and the plateau appears to be compensated locally by thickened crust. We therefore consider this approximation to be valid, but a small contribution of the mantle to the RMBA near the present-day SEIR axis, where the hot spot is supposed to be located, is possible. The variations in crustal thickness refer to the $6 \mathrm{~km}$ average value of our model (Figure 5).

\section{The Amsterdam-Saint Paul/Southeast Indian Ridge Interaction System}

\subsection{Background From Previous Studies}

[10] The Saint Paul and Amsterdam Islands are young $(<0.4 \mathrm{Myr})$ tholeiitic volcanoes [Watkins et al., 1975; Doucet et al., 2004] located $85 \mathrm{~km}$ apart around $37^{\circ} \mathrm{S} 80^{\circ} \mathrm{E}$, roughly $40 \mathrm{~km}$ west of the axis of the SEIR. They are emplaced on a broad volcanic plateau, cut by the SEIR axis in two blocks, one located on the Antarctic plate, where the islands sit, and one in the Australian plate (Figures 1 and 2). The SEIR near the ASP plateau is an intermediary spreading ridge with a nearly constant full rate of $65 \mathrm{~km} / \mathrm{Myr}$. The ridge absolute 

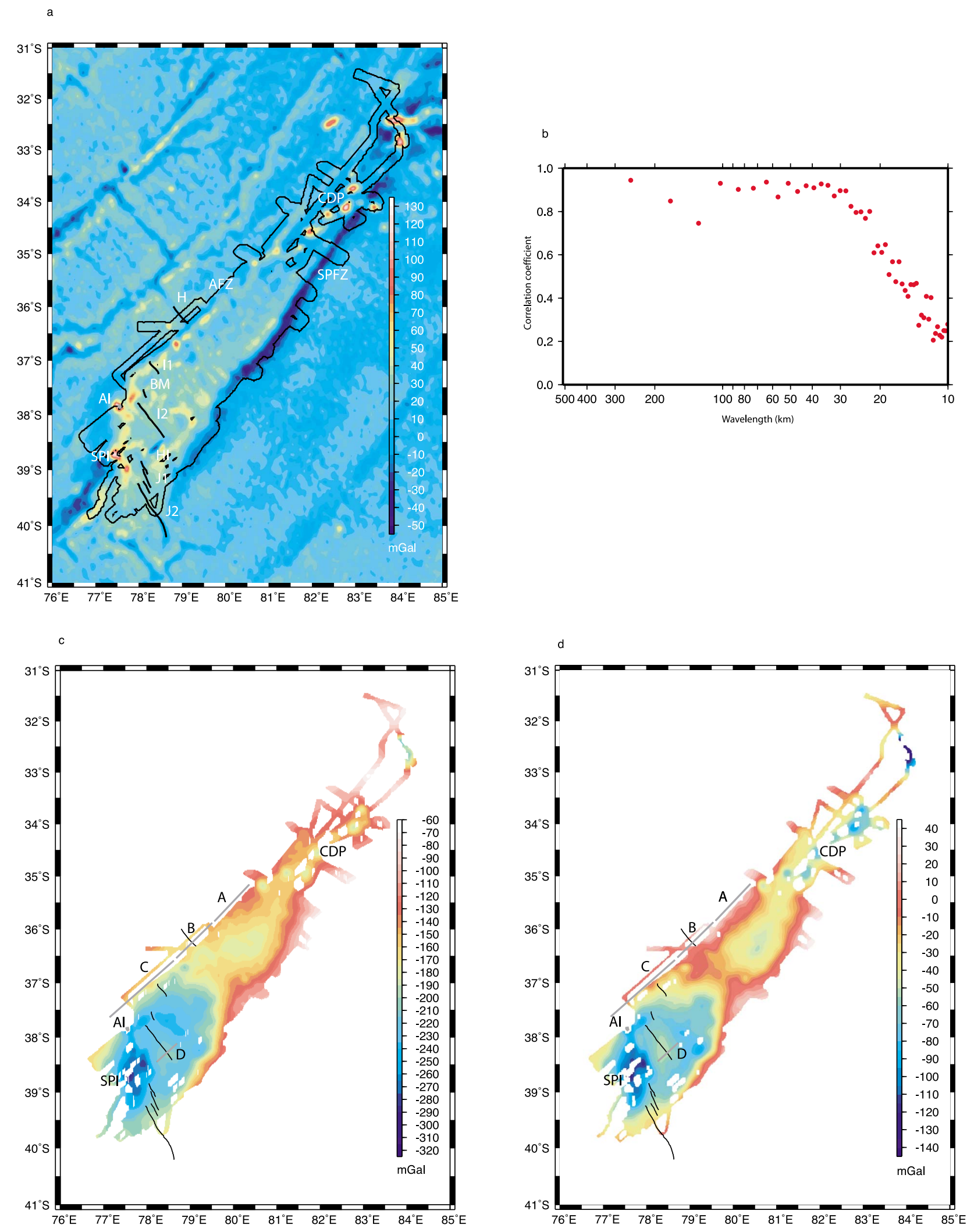

Figure 3. Gravity anomalies for the St. Paul-Amsterdam plateau and the Dead Poets volcanic chain. (a) Merged free air anomaly between satellite [Sandwell and Smith, 1997] and ship data. The thin black line delimitates the area covered by cruises and thus corresponds to ship data. (b) Correlation coefficient between the merged free-air and the bathymetry grids. (c) Mantle Bouguer Anomaly. (d) Residual Mantle Bouguer Anomaly. The present-day SEIR spreading axis is shown by the thick black lines. The labels are as in Figure 2. 


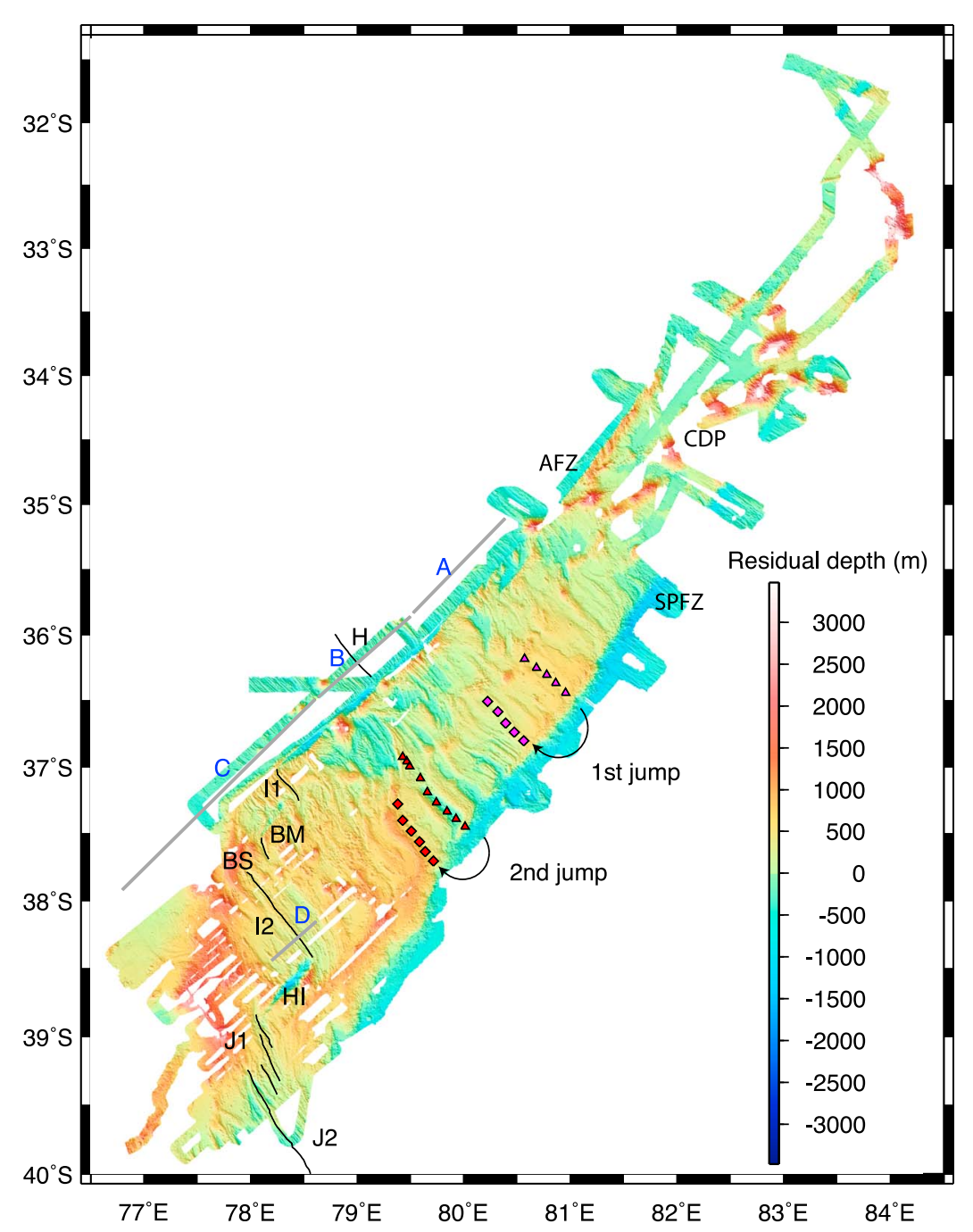

Figure 4. Residual depths computed from the multibeam bathymetry and the removal of a subsidence trend with the square root of age. Depths around "zero" correspond to normal depths for the considered age. Depths were not corrected for the effect of sediment loading, since sediment thickness was found to be relatively uniform and relatively thin over most of the area. Thin black lines, black arrows and magenta, red symbols and labels as for Figures 1 and 2.

migration rate is $35 \mathrm{~km} / \mathrm{Myr}$ to the northeast, and the SEIR is supposed to be migrating away from the ASP hot spot, which would be presently located beneath the Antarctic plate. Available data previous to the PLURIEL cruise show that the youngest part of the plateau is a roughly $150 \mathrm{~km} \times$ $200 \mathrm{~km}$ wide shallow structure, with average depths around $2000 \mathrm{~m}$ [Scheirer et al., 2000]. On the SEIR, the along-axis width of the depth anomaly is roughly $400 \mathrm{~km}$ and the plateau itself is bounded northward by the Amsterdam transform fault and southwards by a system of southeastward propagating rifts [Scheirer et al., 2000] (Figures 1 and 2). Previous gravity studies show that the plateau is locally compensated at crustal levels by a 4 to $6 \mathrm{~km}$ increase in the thickness of the crust [Scheirer et al., 2000]. The thicker crust and shallower depths are located on the Antarctic plate, between the islands (Figure 5) [Scheirer et al., 2000].

[11] The SEIR axis on the ASP plateau is formed by several short segments (Figures 1 and 2), some being relatively short-lived and unstable [Conder et al., 2000]. Segments I1 and $\mathrm{I} 2$ are separated by a recently formed small discontinuity, the Boomerang transform. Segment I2 is composed of two parts, a northern short and unstable portion and a southern, longer portion, that ends on the deep, narrow Hillegom transform, a 2 Myr offset discontinuity, which corresponds to the remaining active portion of the St. Paul Fracture Zone [Conder et al., 2000; Scheirer et al., 2000]. South of this small transform, a series of three en-echelon short rifts form segment J1 (Figures 1 and 2). Segment J2 overlaps with the southern part of segment $\mathrm{J} 1$, forming a propagating rift, which crosses the edge of the ASP plateau and corresponds to a southward along-axis deepening of more than $1000 \mathrm{~m}$ [Conder et al., 2000].

[12] A hot spot origin for the islands of St Paul and Amsterdam and distinct from the Kerguelen hot spot, has been confirmed by geochemical data from the islands, the SEIR segments and submarine volcanoes located on the ASP plateau [e.g., Graham et al., 1999; Johnson et al., 2000; Doucet et al., 2004; Nicolaysen et al., 2007]. The compo- 


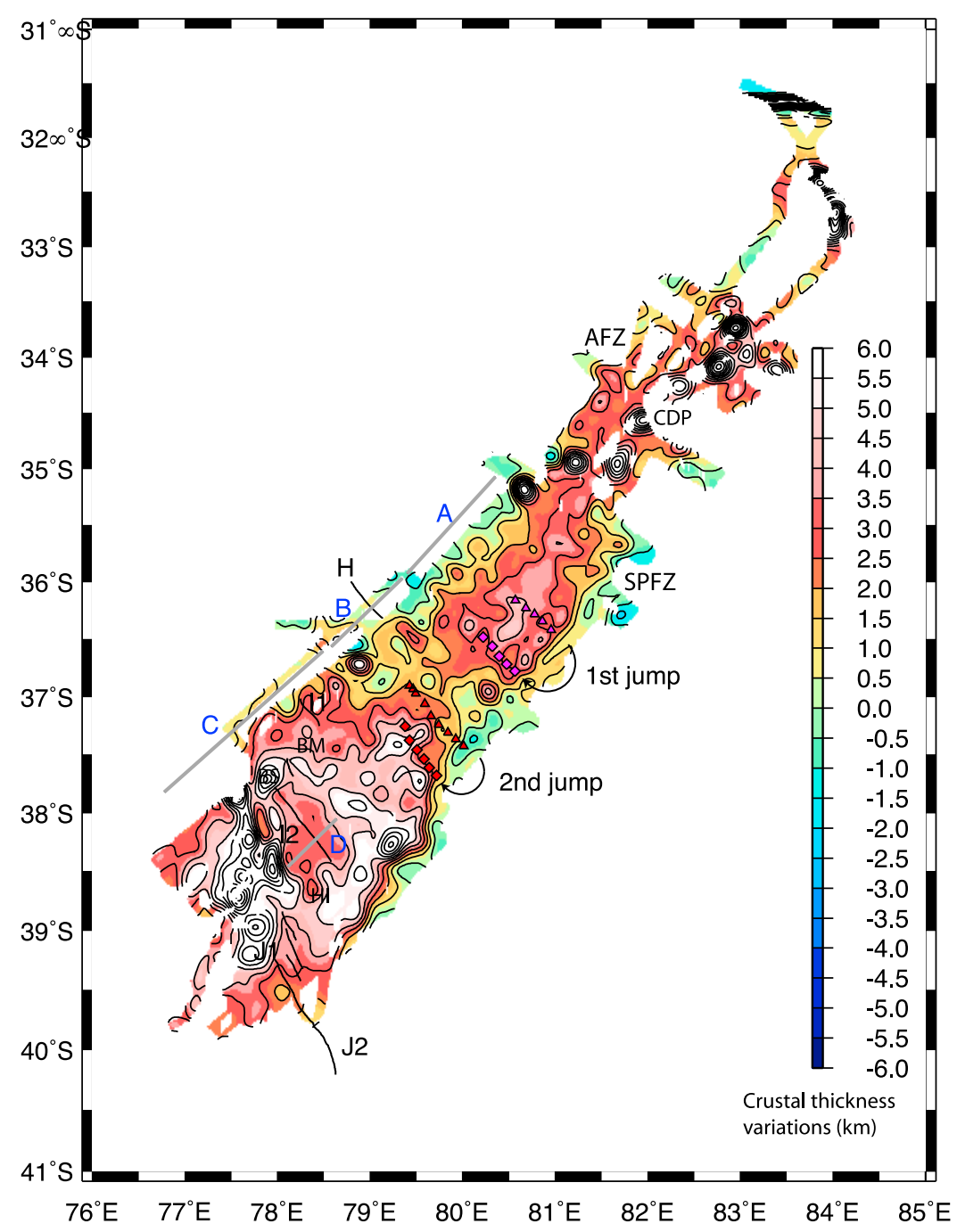

Figure 5. Variations from a constant thickness crustal model inferred from the gravity data collected during the Boomerang and PLURIEL cruises. The average value of the oceanic crust, $6 \mathrm{~km}$, corresponds to the zero value of the scale. Thin black lines, black arrows and magenta, red symbols and labels as for Figures 1 and 2 .

sitional signature of the basalts of the area requires the existence of a heterogeneous ASP component that mixes with the upper mantle in variable proportions [Doucet et al., 2004; Nicolaysen et al., 2007]. Evidence of the ASP component at the southern end of the Ninetyeast Ridge on $38 \mathrm{Myr}$ old volcanism, [Frey et al., 1991; Weis and Frey, 1991] suggests that this source is long-lived. The ASP hot spot anomaly is however supposed to be small. Its along-axis influence extends only up to $300 \mathrm{~km}$ north of the ASP plateau both in terms of geochemistry and ridge axial topography [Graham et al., 1999; Nicolaysen et al., 2007], a short distance compared to other hot spots.

\subsection{The PLURIEL Cruise: Morphology, Gravity Signature and Kinematic Evolution of the Amsterdam-Saint Paul Plateau up to 10 Ma}

[13] Between $80^{\circ} 30^{\prime} \mathrm{E}$ and $87^{\circ} \mathrm{E}$, a volcanic chain, named the "Chain of the Dead Poets," roughly follows the track of possible past locations of the ASP hot spot (Figures 1 and 2). The chain is emplaced along a segment of oceanic lithosphere bounded by the Amsterdam and the St. Paul Fracture Zones (FZ). The volcanoes are located on a regional depth anomaly (Figure 4) that forms an elongated band, 100-200 km wide, extending up to the Ninetyeast and Broken ridges, correlated with a relatively negative regional MBA and RMBA (Figure $3 \mathrm{c}$ and $3 \mathrm{~d}$ ). The crustal thicknesses associated with the edifices are high, consistent with a local compensation (Figure 5). Some of the ages obtained for the chain are surprisingly young ( $\leq 2 \mathrm{Ma})$ [Janin et al., 2009, 2011]. If the volcanoes were the intraplate trace of the ASP hot spot, their ages should increase northeastward and lie between 7 and $14 \mathrm{Ma}$ (Figure 1). Only one of the sampled edifices roughly fits this range, with an age of $8 \mathrm{Ma}$ [Janin et al., $2009,2011]$ although the lack of older ages may be due to a bias introduced by the highly altered state of the samples of the older edifices. Janin et al. [2011] suggest that the chain was formed in two different episodes, the first associated with the intraplate activity of the ASP hot spot, yielding the older volcanoes and the second due to volcanism linked to intraplate deformation associated with the 
diffuse boundary between the Capricorn and Australia plates, which follows a NW trend roughly aligning with the volcanic chain [Royer and Gordon, 1997]. The isotopic composition of the volcanoes confirm their link with the ASP hot spot component, previously identified in the area [Janin et al., 2010].

[14] Southwest of the last volcano, lies a $280 \mathrm{~km}$ long area of seafloor (Figures 2-6, sections A and B) connecting the chain and the near ridge part of the ASP plateau (Figures 2-6, section $\mathrm{C}$ ). This area (sections $\mathrm{A}$ and $\mathrm{B}$ ) is characterized by average depths 500 to $1500 \mathrm{~m}$ shallower than the neighboring corridors south of St. Paul FZ and north of Amsterdam FZ. The morpho-structural pattern is extremely complex [Maia et al., 2007b, 2008; E. Courrèges et al., submitted manuscript, 2011]. A line of small volcanoes trending SW-NE (Figure 6) split the area into two structurally different compartments, probably corresponding to two former ridge segments and to the present-day segments I1 (NW compartment) and I2 (SE compartment) (E. Courrèges et al., submitted manuscript, 2011). Isotopic compositions and ages show that the edifices were emplaced off-axis by the ASP hot spot [Janin et al., 2010, 2011].

[15] The SE compartment displays a regular fabric of abyssal hills that roughly parallels the present-day ridge axis direction. In section A (Figure 6) an area where the residual depth is $400 \mathrm{~m}$ shallower than the environing areas can be seen. This area of relatively shallow depths also corresponds to a smooth seafloor morphology and to a broad relatively negative MBA and RMBA (Figures 3c and 3d, label A). SW of this shallow area, a deeper, rougher zone (Figure 6, label B) is marked by a series of deep grabens and large abyssal hills, which correlates with a relatively positive MBA and RMBA (Figures 3c and 3d, label B). The southern border of this compartment corresponds to a lava-covered slope, showing that flows crossed the St. Paul FZ and accumulated on the floor of the neighboring oceanic corridor (E. Courrèges et al., submitted manuscript, 2011). This pattern could also correspond to large deposits due to the erosion of the higher relief north of the fracture zone, but since no equivalent deposits are seen on the older part of the St. Paul FZ or along the Amsterdam FZ, we interpret these features as evidence of an intense melt production that flowed over parts of the St. Paul FZ. At this latitude, the trace of the fracture zone is shifted southeastward, possibly revealing an increase in the length of the former $\mathrm{I} 2$ ridge segment (E. Courrèges et al., submitted manuscript, 2011).

[16] The compartment located NW of the line of small volcanoes has a more complex morphology. The fabric is suggestive of several episodes of propagation and rotation, yielding interwoven curved "V" shaped abyssal hills. Its central part (Figure 6, label A) is slightly shallower and displays smoother morphology, while area " $\mathrm{B}$ " is deeper and rougher. The differences between the two areas are however much less marked than for the SE compartment. Major "V" shaped features, corresponding to a large deep and associated curved hills, very similar to tips of propagating rifts observed elsewhere [e.g., Blais et al., 2002; Briais et al., 2002], cut across areas where the oblique grain of the ocean floor is highly suggestive of portions of transferred lithosphere. The Amsterdam FZ, the northern limit of the compartment, forms a clear-cut edge and apparently acted as a barrier to the volcanism for most of the evolution of the plateau. The active transform is a very narrow depression, reaching depths of $4000 \mathrm{~m}$. MBA and RMBA display more positive values for this segment (Figures $3 c$ and $3 d$ ).

[17] The transition to the near-axis ASP plateau (Figures 2 to 6 , label $\mathrm{C}$ ) is marked by a wide sigmoïdal ridge in the $\mathrm{SE}$ compartment and by a complex pattern of smaller, shorter, curved hills and deep wide troughs in the NW one. The transition also corresponds to a pronounced southeastward migration of the southern boundary of the ASP plateau over the St Paul FZ, associated with piles of thick lava flows, suggesting a fast increase in the length of the ridge segment associated with a large magmatic activity (E. Courrèges et al., submitted manuscript, 2011) (Figures 2 and 4). Average residual depths in the near axis plateau are comparatively shallower than those of area "A." MBA and RMBA are markedly negative and reveal two blocs separated by a less negative anomaly where the present-day SEIR axis sits (Figure $3 \mathrm{c}$ and $3 \mathrm{~d}$, section D). The presence of several circular volcanic edifices and of volcanic clusters on the NE flank of the plateau (Figures 2, 4, and 6) shows that intense magmatic activity took place off-axis, although the large sigmoïdal ridges, corresponding to highly magmatic abyssal hills reveal that the main bulk of the plateau was built by excess magmatism at the ridge axis, confirming the model proposed by Scheirer et al. [2000]. On the SW flank of the ASP plateau, a NS trending elongated ridge covered by volcanoclastic sediments links the St. Paul and Amsterdam islands (Figures 2 and 4). Volcanism is still active in this part of the plateau, as revealed by the active Boomerang submarine volcano (Figures 1 and 2), located east of Amsterdam Island [Johnson et al., 2000]. Both MBA and RMBA and derived crustal estimates confirm that this part of the plateau displays the thickest crust in the area (Figures 3c, 3d, and 5).

[18] E. Courrèges et al. (submitted manuscript, 2011) show that the ridge geometry was unstable and evolved in time during the past 10 Myr through two southwestward ridge jumps on the SE compartment and a series of propagations on the more complex NW compartment. Their model identifies two ridge jumps. The first at about $6.3 \mathrm{Ma}$ brought the axis $\sim 60 \mathrm{~km}$ to the southwest of its former position and the second, at $3.3 \mathrm{Ma}$ moved it $\sim 30 \mathrm{~km}$ again to the southwest. While the second jump probably brought the ridge axis closer to the probable position of the hot spot and thus is more typical of jumps associated with other ridge-hot spot systems, the first jump very likely increased the distance between the ridge and the hot spot, in contradiction with several observations and models results. E. Courrèges et al. (submitted manuscript, 2011) suggest that a change in relative plate motion might have triggered the jump, but that for this to happen, the influence of the ASP hot spot at the ridge axis must have been small at the time.

\section{Time Evolution of the Crustal Thickness and Residual Depth Anomalies}

[19] In order to evaluate the temporal evolution of the ridge accretion pattern, we calculated averaged values for crustal thickness variations and residual depths at each magnetic anomaly identified, considering a $\pm 0.3 \mathrm{Myr}$ bin. The values were computed using age identifications interpolated to form a continuous isochron, when possible. Crustal and depth values were sampled on this age interval from the 


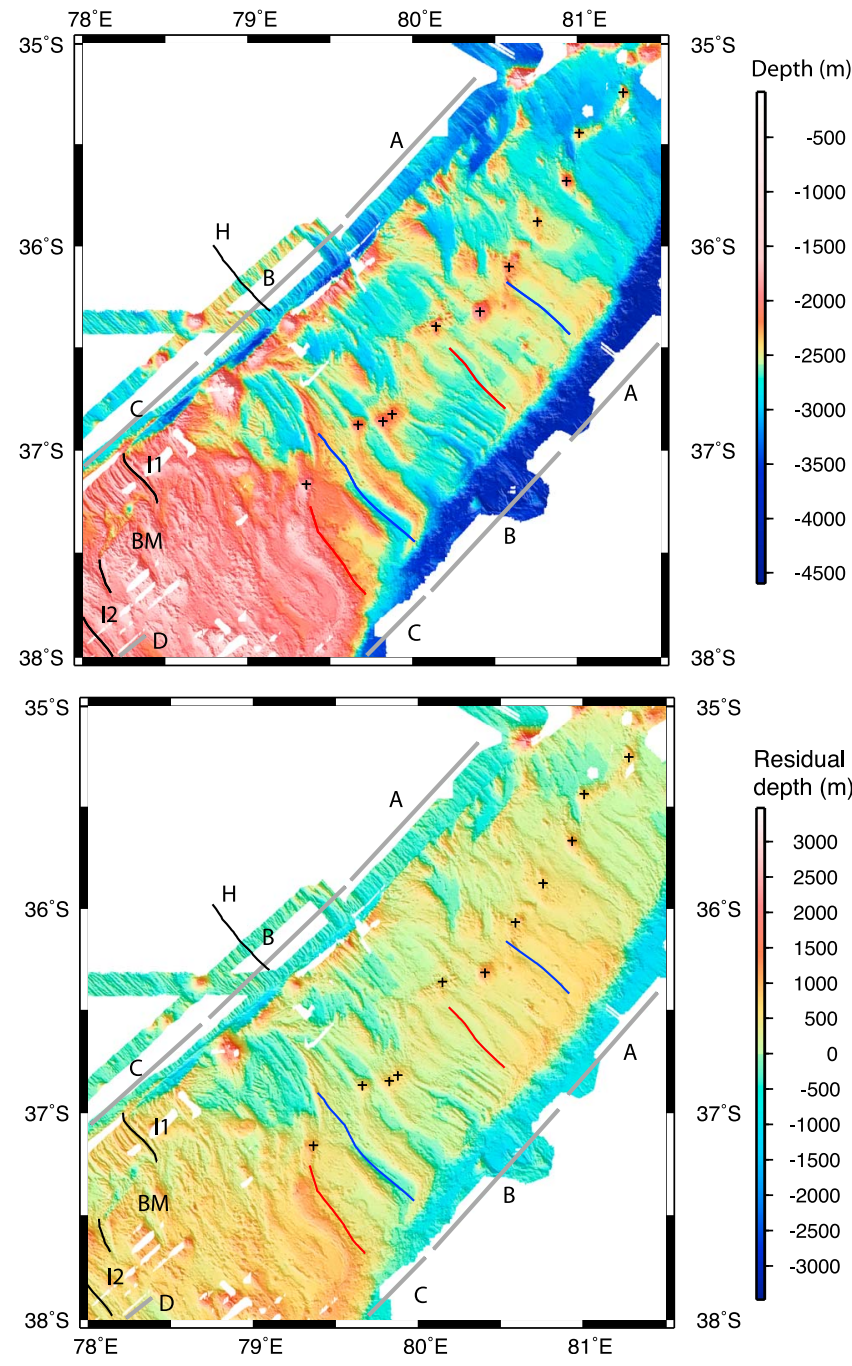

Figure 6. (top) Multibeam bathymetry and (bottom) residual bathymetry of the ASP plateau between the near axis plateau and the volcanic chain. Labels A, B, C and D are discussed in the text. Thin black lines show the presentday SEIR axis [Conder et al., 2000; Scheirer et al., 2000]. Crosses show the small volcanoes and volcano clusters separating the two paleo-ridge segments (see text for discussion). Thin blue lines show the location of the abandoned spreading axes and thin red lines the location of the corresponding new axes for the two ridge jumps identified by E. Courrèges et al. (submitted manuscript, 2011). Labels are as in Figures 1 and 2.

available grids and averaged to obtain the displayed points. Areas close to the volcanoes of the central line, linked to the off-axis activity of the hot spot [Janin et al., 2011] were removed from the data set to avoid introducing biases, since we are interested on the average values of the crust formed at the ridge axis. These values are plotted as a function of time in Figure 7. The analysis of the residual bathymetry (Figures 4, 7a, and 7b) and of the crustal structure derived from the RMBA (Figures 5, 7a, and 7b) shows two periods of relative positive depth anomalies corresponding to periods of thick crust around 1-3 Ma and $7 \mathrm{Ma}$. The correlation thus points to two periods of stronger magmatic activity at the SEIR axis which correspond to areas " $A$ " and " $C$ " separated by a period of more tectonic ridge activity, corresponding to the deeper and rougher topography of area "B" (Figures 4, 5, 6, and 7b). Compared to an average $6 \mathrm{~km}$ crust, crustal thickness inferred from the RMBA yields an excess crust of up to $6 \mathrm{~km}$, (Figures 5 and $7 \mathrm{~b}$ ) and $4.5 \mathrm{~km}$ in average (Figure 7a) for the near axis part of the plateau (area "C") and smaller crust excess of up to $4.5 \mathrm{~km}$ (Figures 5 and $7 \mathrm{~b}$ ) and 2 to $3 \mathrm{~km}$ in average (Figure 7) for area "A," suggesting higher melt production for the recent part of the plateau (Figures 5, 7a, and 7b). The first evidence of a positive depth anomaly at the SEIR axis and of an increase in the thickness of the crust appears around $\sim 9.7 \mathrm{Ma}$ (Figures $7 \mathrm{a}$ and $7 \mathrm{~b}$ ). Ridge depths diminish, the morphology becomes smoother, which is suggestive of small axial highs, and the thickness of the crust increases (area "A") until $\sim 6.3 \mathrm{Ma}$ (Figures 6, 7a, 7b, and 8). At this epoch the first ridge jump intervened. It corresponds to the beginning of a $\sim 3 \mathrm{Myr}$ long period when the magmatic production diminishes and the tectonic processes dominate (area "B" and Figures 5, 6, 7a, $7 \mathrm{~b}$, and 8 ), yielding a deeper ridge axis and rough morphology, suggestive of rift valleys. Crustal thickness values remain about 1 to $2 \mathrm{~km}$ above the $6 \mathrm{~km}$ average. At about 3.3 Ma, the ridge jumps again, shortly after the beginning of a second period of increased crustal production (area "C"), which created the shallowest part of the ASP plateau (Figures $5,6,7 \mathrm{a}, 7 \mathrm{~b}$, and 8 ). This period lasted roughly until $0.9 \mathrm{Ma}$, when the breakup of the plateau started from south to north [Conder et al., 2000; Scheirer et al., 2000] due to the northward propagation of the I2 SEIR segment (Figures 2-6, area $\mathrm{D}$ ). As previously described, the crust created during this second period is thicker than that created during the first (9.7-6.3 Ma), and the average residual depths diminish (Figures $7 \mathrm{a}$ and $7 \mathrm{~b}$ ).

[20] Although depth and gravity derived crustal thickness in the ASP area varied during the last $10 \mathrm{Myr}$, they remained significantly above the usual values for non hot spot-influenced ridges [e.g., Schilling, 1991] with an average of $9.1 \mathrm{~km}$ for the crustal thickness and an average residual depth of $1050 \mathrm{~m}$. During most of this $10 \mathrm{Myr}$ period, the SE segment of the SEIR in the ASP plateau (corresponding to present-day segment I2) often displays thicker crust and shallower depths than the NW segment (corresponding to segment I1) (Figures 7a and 7b), suggesting that for most of the time, magmatism was stronger in the south than in the north of the ASP lithospheric compartment. For the period between 2.5 and $9 \mathrm{Ma}$, the NW segment is in average $230 \mathrm{~m}$ deeper than the SE. The morphologic differences between the St. Paul FZ, crossed by lava flows, and the sharp Amsterdam FZ agree with this observation (E. Courrèges et al., submitted manuscript, 2011). However, for more recent periods, magmatism appears to be stronger in the north. The most recent volcanic activity is located at Boomerang Smt. [Johnson et al., 2000] and the nearby segment of the Amsterdam FZ displays lava flows similar to those observed across the older parts of the St Paul FZ. The breakup of the plateau (Figures 2-6, area D) and the development of the Hillegom Trough, suggest the beginning of a colder regime in the south, allowing the formation of a new transform fault. As already noticed by Scheirer et al. [2000], this new transform discontinuity forms in the prolongation of the trace of the St. Paul FZ. 

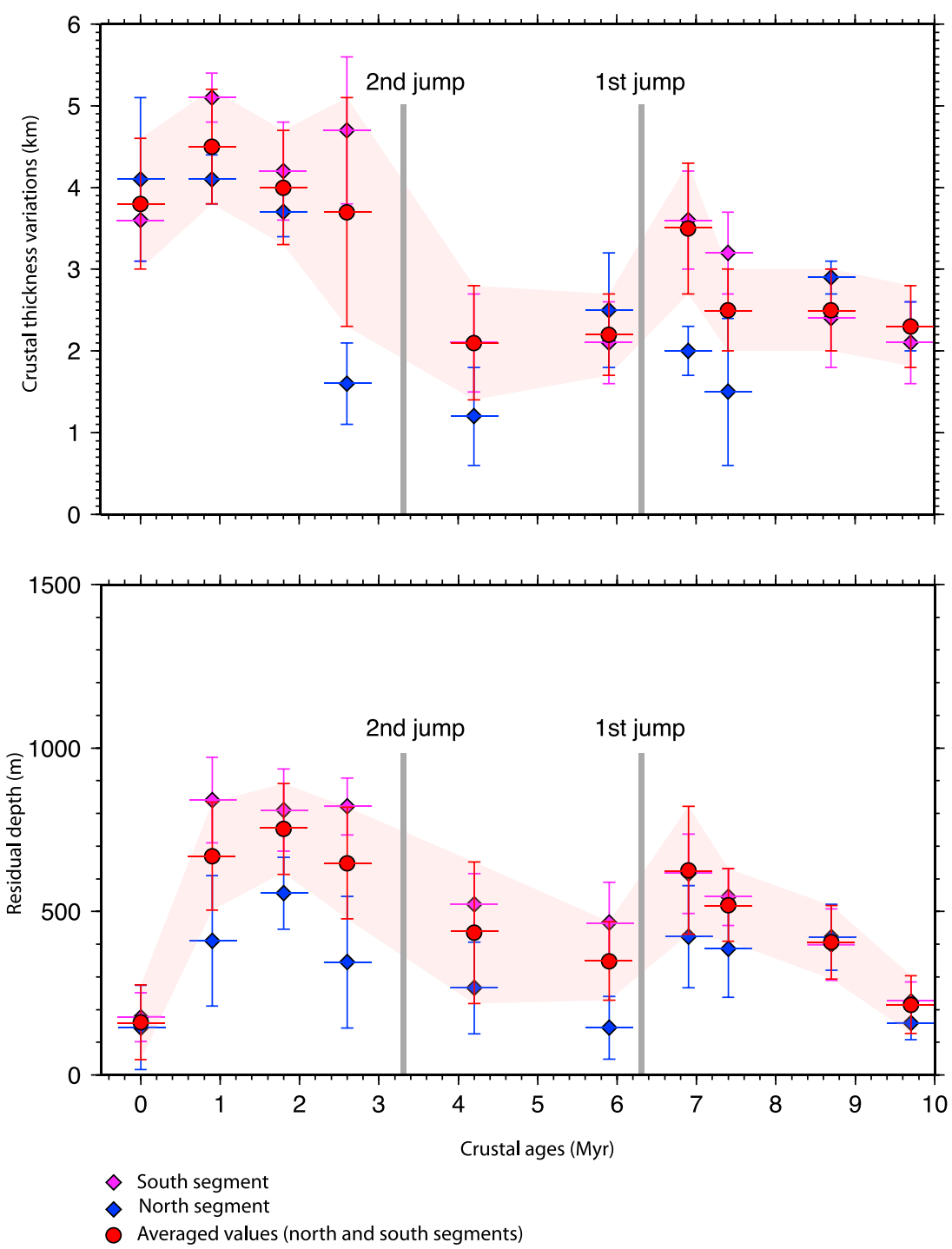

Figure 7a. (top) Crustal thickness variations from an average of $6 \mathrm{~km}$ and (bottom) residual depths versus time in Myr. A $0.3 \mathrm{Myr}$ bin width was considered for each isochron (time axis error bar). Crust and depth axes error bars correspond to a $1 \sigma$ interval. Red circles represent averaged values for the whole ASP lithospheric compartment, with the corresponding $1 \sigma$ interval represented by the light red shade. Magenta lozenges represent values for the Southeast segment and blue lozenges, values for the Northwest segment. Gray vertical bars represent the periods of the two ridge jumps discussed in the text.

[21] Correlations between axial depth, ridge morphology and crustal thickness are observed for different spreading ridges [e.g., Lin et al., 1990] and reflect the balance between tectonic and magmatic processes and the variations in the amount of melt supply at the ridge axis.. The link between depth, morphology and crustal thickness in the ASP plateau confirms that the process at the origin of the anomalous values is an increase in the melt production beneath the ridge that, although varying with time, lasted for $\sim 10 \mathrm{Myr}$. The high melt availability at the ridge axis probably results both from excess temperatures and from the presence of fertile mantle material due to the ASP hot spot [Niu et al., 2001]. If we consider that the crustal thickness depends only on mantle temperature [Chen, 1996; Chen and Lin, 2004], during the first magmatic phase, between 6.3 and $9.7 \mathrm{Ma}$, the temperature increase at the ridge axis reached $\sim 70^{\circ} \mathrm{C}$, while for the second magmatic phase (3.3 to $0.9 \mathrm{Ma}$ ) excess temperatures were is in the order of $100^{\circ} \mathrm{C}$. Between the two phases, mantle temperatures at the axis were about $40^{\circ} \mathrm{C}$ above that needed to create a $6 \mathrm{~km}$ thick crust. These values correspond to an upper bound, since changes in the composition of the mantle were not taken into consideration.

[22] At intermediate spreading rates, ridge morphology and crustal structure significantly change due to small variations in the axial thermal structure [e.g., Chen and Morgan, 1990; Morgan and Chen, 1993; Chen and Lin, 2004]. Changes in the axial morphology and crustal thickness are observed along the SEIR at nearly constant spreading rates, supposedly due to along-axis variations in mantle temperatures related to the influence of hot spots (Kerguelen and ASP) and of the AAD "cold spot" [Sempéré et al., 1997; Ma and Cochran, 1996; Cochran et al., 1997]. The transition from 


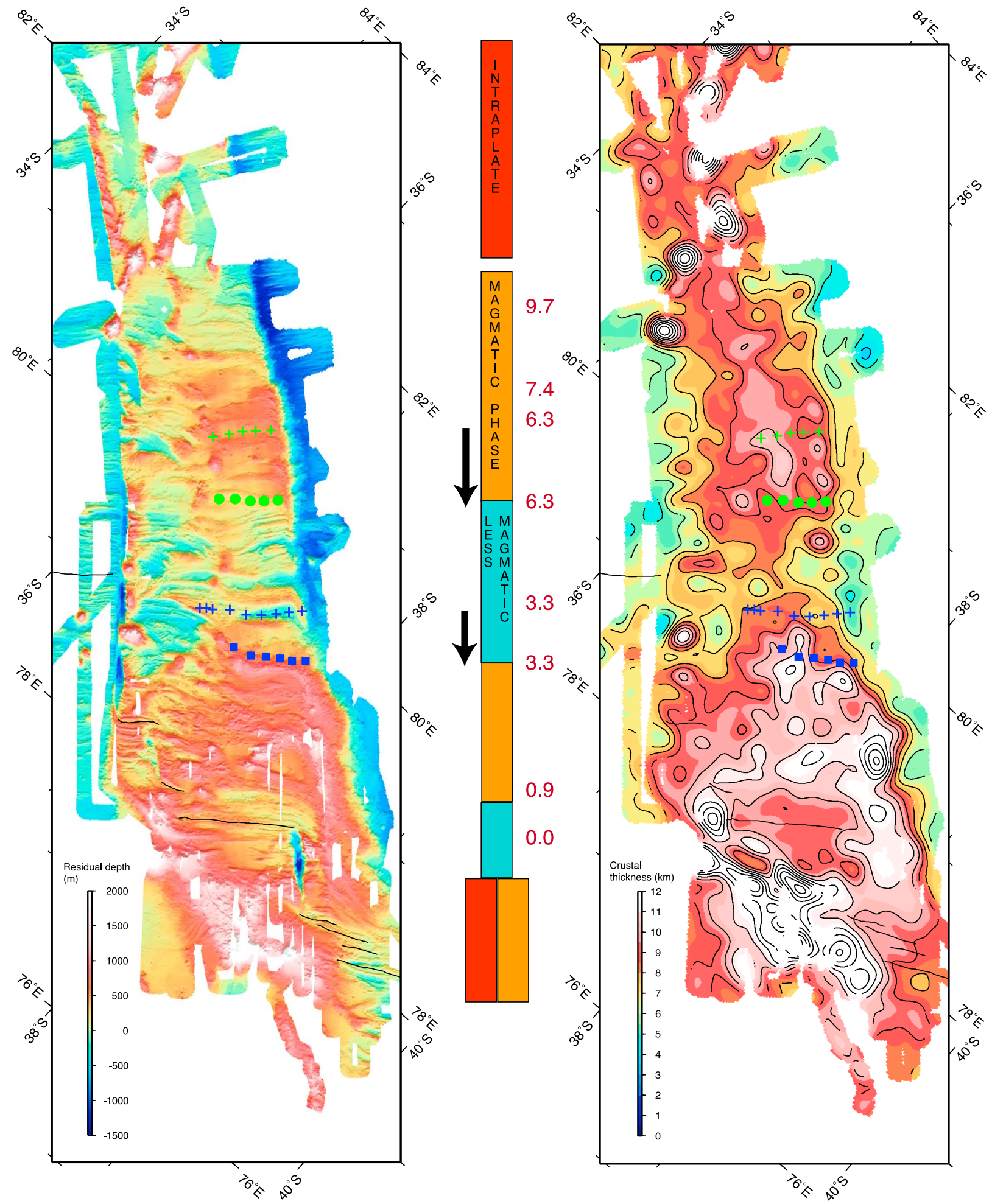

Figure 7b. Synthesis of the time evolution of the crustal structure of the ASP plateau. (left) The residual bathymetry is represented and (right) the corresponding crustal thickness variations are shown. The central vertical scale shows the alternance between the magmatic (orange blocks) and less magmatic (more tectonic, blue blocks) ridge phases discussed in the text as well as the intraplate phases (red blocks), corresponding to the building of the chain of the Dead Poets and of the present-day volcanic islands of Amsterdam and St. Paul. These islands were built on a block of the plateau, therefore two labels (for the two different phases) are shown. The ages correspond to selected identified magnetic anomalies and to the ridge jumps, represented in green (first jump) and blue (second jump). The arrows show the direction of the jumps. 
axial highs to shallow rifts happens quickly, as a response of the accretion mechanism to small changes in the axial thermal structure [Ma and Cochran, 1996; Chen and Lin, 2004]. We observe here, through a period of $10 \mathrm{Myr}$, a similar variation in the ridge axial morphology and in crustal thickness. The shallow depths and thick crust of the first magmatic phase are associated with a smooth morphology, often linked with axial highs and fast spreading rates (Figure 8). A small graben $200 \mathrm{~m}$ deep marks the emplacement of the failed axis. The abyssal hills, 100 to $250 \mathrm{~m}$ high, display the characteristic asymmetric shape, with the fault scarp facing the ancient axis. This morphology is similar to what is observed in some parts of the SEIR axis by Shah and Sempéré [1998] and described as a rifted high, where the graben results from a decrease in the axial magmatic activity. The lowmagmatic phase is characterized by deeper grabens, closely spaced faults and rougher morphology (Figure 8), evidence of a rift valley morphology, corresponding to a "colder," more tectonic period. The abrupt change from smooth to rough morphologies that accompanied the decrease in the thickness of the crust confirm that intermediate spreading ridges can react quickly to variations in melt supply, similar to what is observed for the Galapagos Spreading Center [Chen and Lin, 2004].

[23] Axial morphology depends on mantle temperature and melt supply, which controls the strength of the lithosphere but also the amount of magmatism at the axis [Chen and Lin, 2004; Behn and Ito, 2008; Ito and Behn, 2008]. Recent models revealed that fault parameters are primarily controlled by the rate of magma injection (fraction of the total spreading rate accommodated by magma accretion) and secondarily by the axial lithospheric thickness [Behn and Ito, 2008]. Thicker axial lithosphere result in smaller fault spacing and heave, but also in a total axial valley relief that is higher than in thinner lithosphere, which is coherent with our observations (Figure 8). The transition from axial highs to rift valleys is also controlled by the magmatic budget at the axis, and occur when the duration of the magmatic phases during the magmato-teconic cycle diminishes, and the periods of tectonic extension increase. Thinner axial lithosphere and elevated axial topography correlate with longer magmatic periods [Ito and Behn, 2008]. At intermediate spreading rates, a small increase in the melt supply will increase the amount of magma injection and the length of the magmatic period, thus allowing a quick change from a rift valley to an axial high (Figure 8). Our morphological observations are thus coherent with a thin lithosphere and pronounced magmatism during the two magmatic phases (6.3-9.7 Ma; 3.3-0.9 Ma) and with thicker lithosphere and smaller magmatism during the low-magmatic phase (6.3-3.3 Ma). The ASP hot spot certainly contribute to this by increasing the temperature beneath the ridge axis, which will both thin the axial lithosphere and increase the amount of melt supply. At intermediate rates, where the threshold between rift and non-rift morphologies is narrow, the effect of a hot spot, even weak, would have critical effect on the ridge structure [Chen and Lin, 2004].

[24] Highly variable morphologies have been observed for neighboring segments along spreading ridges [e.g., Thibaud et al., 1998; Shah and Sempéré, 1998; Ma and Cochran, 1996], linked with differences in the thermal state of each individual segment. The differences between the SE and the
NW segments of the ASP plateau can result from a highly localized influence of the ASP hot spot at the SE segment. This segment, disposing of a higher melt supply, would develop a "hot/fast ridge morphology," while the NW segment would keep a "cooler" morphology. A possible mechanism for such marked differences in melt availability can be the different position of each segment related to the ridge absolute migration [Carbotte et al., 2004]. Taking the SEIR axis at the ASP lithospheric compartment as a reference (segments I1 and I2), the SEIR axis is offset westward south of the St Paul FZ (segments J1 and J2) and eastward north of the Amsterdam FZ (segment H) (Figure 1). This relative geometry remained the same during the past $10 \mathrm{Myr}$ with the offset at the St. Paul discontinuity being larger than that at the present-day Hillegom transform. The SE segment (corresponding to I2) has thus always been in a "leading position" compared with the NW segment (corresponding to I1), which was in a "trailing position." In this case, asymmetry in the mantle upwelling, due to the ridge absolute motion, together with the proximity of a hot spot would induce lateral melt migration across the discontinuities and helps to focus melts in the SE segment, leading to the observed differences [Katz et al., 2004].

[25] Axial plateaus are associated with the disappearance of clearly defined and stable axial segmentation. Large offset discontinuities, such as the Pico-Gloria FZ at the slow spreading Mid-Atlantic Ridge south of the Azores plateau [Gente et al., 2003] may be wiped out by the thermal effect of the hot spot. This change in the structure of the spreading center reflects a profound modification of the axial lithosphere and of the magmatic budget. At the ASP system, the ridge segmentation is not well defined for the last $10 \mathrm{Myr}$. The discontinuity between the SEIR paleosegments of the ASP plateau, only becomes well defined in recent times, with the establishment of the small Boomerang transform between the present active segments I1 and I2 [Conder et al., 2000; E. Courrèges et al., submitted manuscript, 2011]. The St Paul transform was unstable in the past (E. Courrèges et al., submitted manuscript, 2011) until the decrease in the crustal thickness that started at $0.9 \mathrm{Ma}$ and the return to a less magmatic accretion regime (Figures 4,5 , and $7 b$ ) resulted in the return of the conditions favoring the appearance of a transform discontinuity, the Hillegom transform. A conclusion is that the SEIR in the ASP area is presently undergoing a cold regime, allowing the re-establishment of an axial segmentation with transform faults.

\section{Relative Influence of Ridge-Hot Spot Relative Movement and of Temporal Variations in the Strength of the ASP Hot Spot on Axial Plateau Formation}

[26] At the ASP-SEIR system, the observations (depth anomalies, ridge morphology and the thickness of the crust) point to a temporal variation of the melt supply to the ridge axis. Two factors must be considered to explain the observed pattern. The first is the temporal variation in the distance between the ridge axis and the hot spot. The second is the variation with time of the strength of the source of the hot spot, the "hotspot source pulses."

[27] In order to evaluate the evolution of the relative positions of the SEIR and the ASP hot spot through time, we 


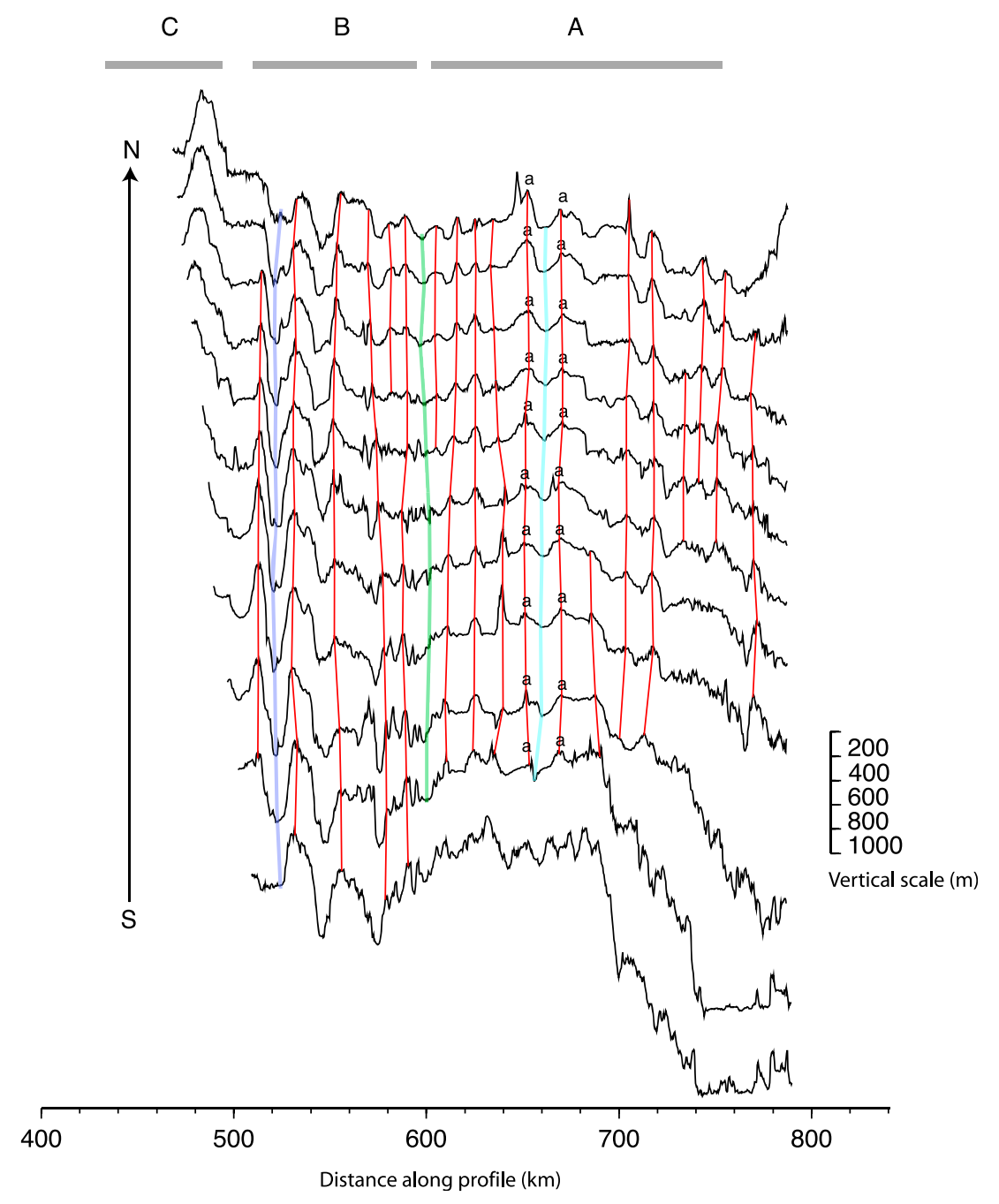

Figure 8. Bathymetric profiles showing the variation in the morphology from the edge of the young plateau (second magmatic period, area "C") to the edge of the first magmatic period (area "A"). The transition between the low magmatic phase ("B") to the first magmatic phase ("A") is clearly seen from the change in the roughness of the topography. Both fossil rifts are shown in blue colors, light blue for the 6.3 Ma rift and dark blue for the 3.3 Ma rift. The green line locates the position of the new ridge axis at the end of the 6.3 Ma jump. The $3.3 \mathrm{Ma}$ rift corresponds to a deep asymmetric graben, flanked by steep fault scarps. The $6.3 \mathrm{Ma}$ rift corresponds to a small graben on top of an axial high, flanked by remarkably symmetric abyssal hills (letter "a"), displaying the characteristic asymmetric shape.

reconstructed the possible positions for the hot spot. K-Ar dating performed on PLURIEL samples [Janin et al., 2009, 2011] show that the age distribution along the volcanic chain does not follow a regular age progression. Still, ages of some edifices roughly fit with the ASP hot spot track and whether or not this coincidence is significant depends on the reliability of the predicted tracks. Uncertainties in a hot spot track are difficult to assess, since it requires several assumptions or information which are either unavailable, or not available for the same ages, or unknown: (1) the current location of the hot spot, (2) uncertainties in the absolute motion of the reference plate relative to the hot spot frame, (3) uncertainties in the relative plate motions that link, in our case, the Australian plate to the reference plate, (4) whether or not the considered hot spot is stationary, or stationary with respect to the considered hot spot reference frame [e.g.,
Steinberger and $O$ 'Connell, 1998; Koppers et al., 2001]. Furthermore, since there are only few dated hot spot tracks, all hot spot kinematic models are generally intrinsically linked to a relative plate motion model. The HS3-Nuvel1-A [Gripp and Gordon, 2002] model is based on Nuvel1-A and a selection of hot spot tracks and assumes a rate and direction of absolute motion steady for the past $5.3 \mathrm{Ma}$ (during which the considered hot spots appear stationary). The motion of the Australian and Antarctic plates can be derived directly by extrapolating the rates of motion to $30 \mathrm{Ma}$. Since we know that the relative plate motions were not stable for the last $30 \mathrm{Ma}$, we kept the HS3-Nuvel1A reference frame for the Pacific plate, which we combined with the PacificAntarctica-Australia plate circuit [Cande and Stock, 2004]. By doing so, we allow the relative plate motion to vary through time, whereas the absolute motion is assumed stable 
in rate and direction for the last $30 \mathrm{Ma}$ (and still relies on the Nuvel1-A model). We also tested the models compiled by Torsvik et al. [2008] which include an African fixed hot spot frame, an African moving hot spot frame, a global moving hot spot frame and a global hybrid hot spot frame (with paleomagnetic constraints). Each of these models is averaged at a $5 \mathrm{Ma}$ interval. For each hot spot track, we assumed the current location of the ASP hot spot at $38^{\circ} 30^{\prime} \mathrm{S} / 77^{\circ} 36^{\prime} \mathrm{E}$, between the islands of Amsterdam and St Paul, and a hot spot "diameter" of $80 \mathrm{~km}$, among possible sizes commonly admitted in the literature for small hot spots [e.g., Ito et al., 2003]. For the last $8 \mathrm{Ma}$, except for the "African fixed hotspot frame" which surprisingly predicts a track off the ASP plateau, all the other models are fairly consistent and similar to Figure 1, which combines HS3-Pacific with the Pacific-Antarctic-Australia plate circuit. Prior to $8 \mathrm{Ma}$, differences in the predicted positions of the hot spot increase, all the tracks extending NE-SW from the Ninetyeast Ridge. For the purpose of our discussion, we consider that the hot spot track represented in Figure 1 is a plausible averaged model, which, for any given time, provides the possible location of the hot spot within a 100 to $120 \mathrm{~km}$ diameter. The motion of the ASP hot spot inferred by Janin et al. [2011] remains below this uncertainty. The SEIR past positions were derived from the magnetic anomaly crossings of E. Courrèges et al. (submitted manuscript, 2011) (Figure 2). The model is represented in Figure 9 for key time stages and a cartoon is shown in Figure 10.

[28] Plateaus are built when enough hot spot material is drained toward the ridge axis to allow a large increase of crust production. The connection is established when the two melting zones are close enough to interact or when the slope at the base of the lithosphere becomes steep enough to act as a drain [Maia et al., 2001; Sleep, 2002]. The distance at which it begins relates to the size of the hot spot source and to both the ridge spreading rate (which shapes the slope of the bottom of the lithosphere) and the velocity of the ridge-hot spot relative movement. The first magmatic phase (area "A") may correspond to this early stage of the ridgehot spot interaction, with a hot spot still located to the NE of the ridge axis (Figures 9a and 10b). Several models show that slower spreading rates favor ridge-hot spot interaction and along axis flow and that slow ridge-hot spot motion strengthens the connecting flow [e.g., Ribe and Delattre, 1998; Albers and Christensen, 2001; Sleep, 2002]. Thus, the slower the spreading rate, the easier the hot spot material will be drained toward the ridge axis and the slower the ridge velocity, the higher the amount of hot spot material that will arrive at the axis. So, at slow or intermediate rates the connection between the hot spot and the ridge is established at larger distances than at fast rates and an early building of the plateau will be favored, as is observed here. The first period of increase in the ridge magmatic budget may also be related to a period when the hot spot source is relatively strong, able to enhance the melting at the ridge even still away from it. During this first period, the distance between the hot spot and the ridge continuously diminishes while the axial magmatic budget increases, forming thick crust and smooth morphology (Figures 10b and 10c). The older volcanoes of the Dead Poets intraplate chain were probably formed before the SEIR started to interact with the
ASP hot spot or at the earlier times of this first phase (Figure 10a).

[29] The first ridge jump at 6.3 Ma (Figures $9 \mathrm{~b}$ and 10d) occurred when the connection between the ridge and the hot spot source was weak, the hot spot being located off-axis. The jump, by increasing the distance between ridge and hot spot may have contributed to reduce the connecting flow, leading to the low-magmatic phase (area "B") (Figures 9c, $9 \mathrm{~d}$, and 10e). During most of the low-magmatic phase, the hot spot center remained relatively close to the ridge axis and, supposedly, melting rates could be enhanced if the strength of the hot spot source was high enough. One possible explanation for this low magmatic budget is a period of weak hot spot source flux. Although the jump could have temporally interrupted the delivery of magma to the ridge axis, bringing the ridge above a less hot mantle, it is unlikely that, due to the short distance between the hot spot source and the ridge, this interruption would last for the entire period. Both the first jump, and the low magmatic budget of this phase do not fit the scheme derived from observations and models. Ridge jumps and propagations related to ridge-hot spot interactions more commonly tend to bring the ridge axis back near the hot spot when the ridge starts to migrate away from it [Small, 1995; Garcia et al., 2003; Nakanishi et al., 1999]. Recent numerical models suggest that ridge jumps occur preferentially at short distances from the failing spreading axes and that higher plume fluxes increase their probability [Mittelstaedt et al., 2008]. According to E. Courrèges et al. (submitted manuscript, 2011) such a mechanism is a probable explanation for the $3.3 \mathrm{Ma}$ (second) ridge jump, but not for the $6.3 \mathrm{Ma}$ jump. The authors favor a small change in the relative motion between Antarctic and Australia as a possible mechanism for the latter. It is however probable that a strong ridge-hot spot connection would maintain the spreading axis close to the hot spot source, thus hindering the jump. A decrease in the ASP hot spot source strength, and the relatively large distance separating the hot spot and the ridge at $6.3 \mathrm{Ma}$ would allow for the ridge to more easily migrate away from the hot spot, since both factors would contribute to a weak ridge-hot spot connection. Thus, the change in regional plate motion would be the dominant cause of the jump away from the hot spot rather than the process of hot spot-induced rift relocation as simulated in models. A period of low hot spot source flux could thus explain the low-magmatic phase and also facilitate the first ridge jump.

[30] The second ridge jump at the beginning of the second magmatic phase (area " $C$ "), (Figures 9d and 10f) slightly readjusted the spreading axis position close to the center of the hot spot. An increase in the strength of the hot spot source may have triggered the second jump and may also partly explain the strength of the second magmatic period. This second phase also corresponds to an on-axis position of the hot spot source and thus to a strong increase in the melt supply (Figures 9d, 9e, and 10f). Thus, the thick crust and shallow bathymetry of the second magmatic phase are probably due to both an increase in the strength of the hot spot source and to a near axis/on-axis position for the hot spot.

[31] Since $\sim 1$ Ma a new low-magmatic phase started (area "D"), revealed by the splitting of the southern part 
a

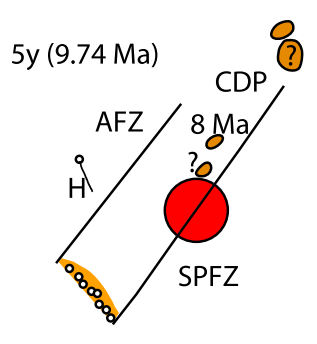

b

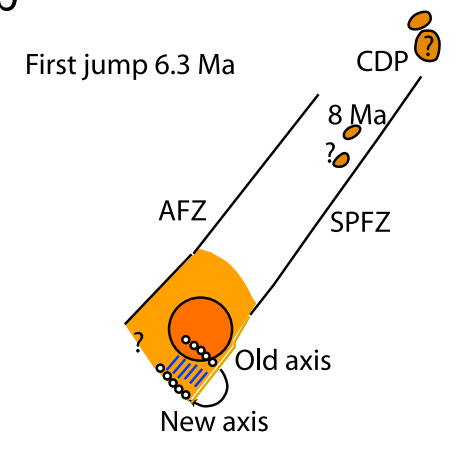

C

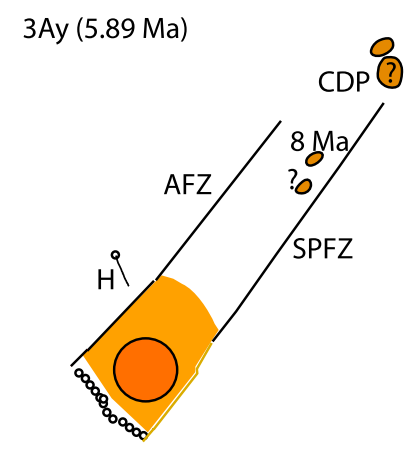

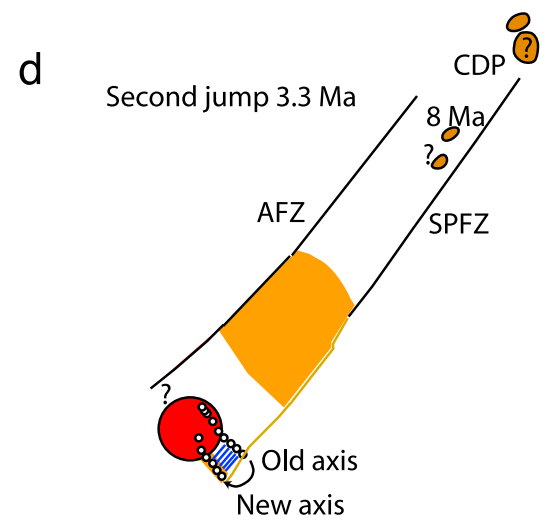

e

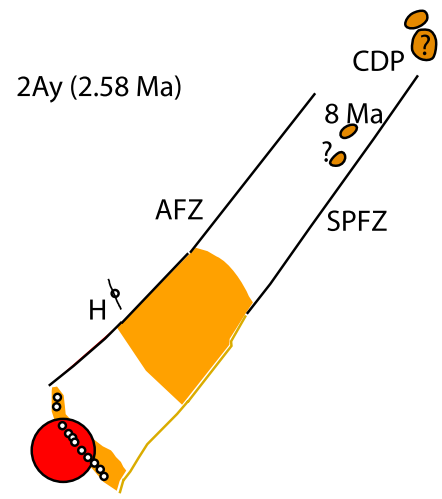

f

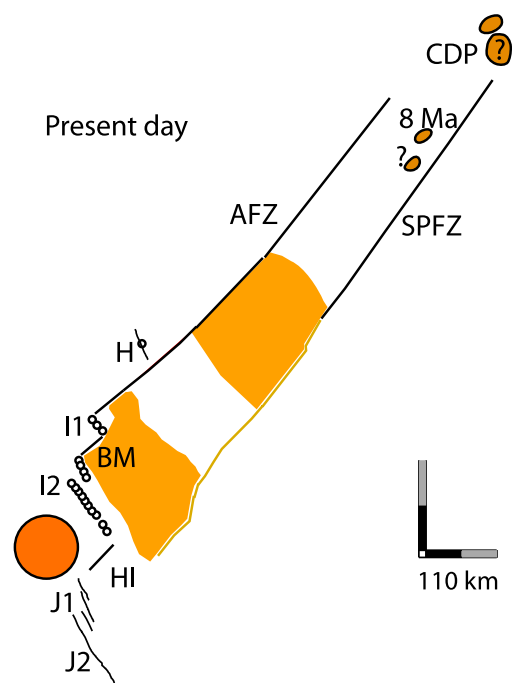

Figure 9. (a-f) Schematic evolution of the ridge hot spot interaction. Kinematic reconstructions for 9.7 (5y), 6.3 (first ridge jump), 5.89 (3Ay), 3.3 (second ridge jump) 2.58 (2Ay) Ma and present, using the magnetic identifications (E. Courrèges et al., submitted manuscript, 2011) and a model for hot spot location. Ridge positions were derived from magnetic anomaly picks (gray dots). The hot spot "diameter" $(80 \mathrm{~km})$ is taken from possible sizes commonly admitted in the literature, considering that ASP is probably small. The thick black lines mark the location of St Paul (SPFZ) and Amsterdam (AFZ) fracture zones, when they are well defined in the bathymetry. The brown line marks the emplacement of the St Paul FZ when it is covered by lava flows. The brown circles show the location of the volcanoes associated with the intraplate activity of the hot spot. The light orange patches show the areas of thick crust and shallow, smooth bathymetry associated with the magmatic phases. Blue hatches show the portions of transferred lithosphere. The different colors for the circle representing the hot spot represent the periods of strong (red) and weak (orange) flux. Ridge segments and axial discontinuities are labeled as in previous figures. 
a

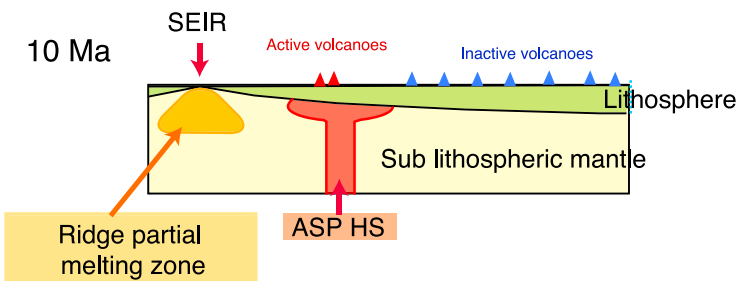

b

C

d

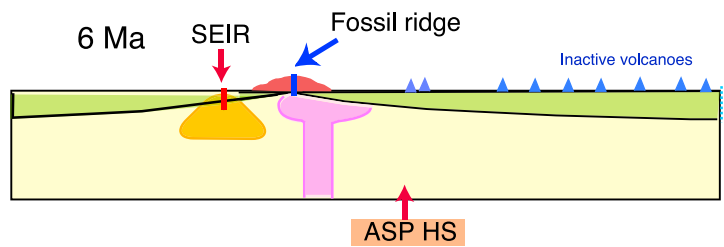

e
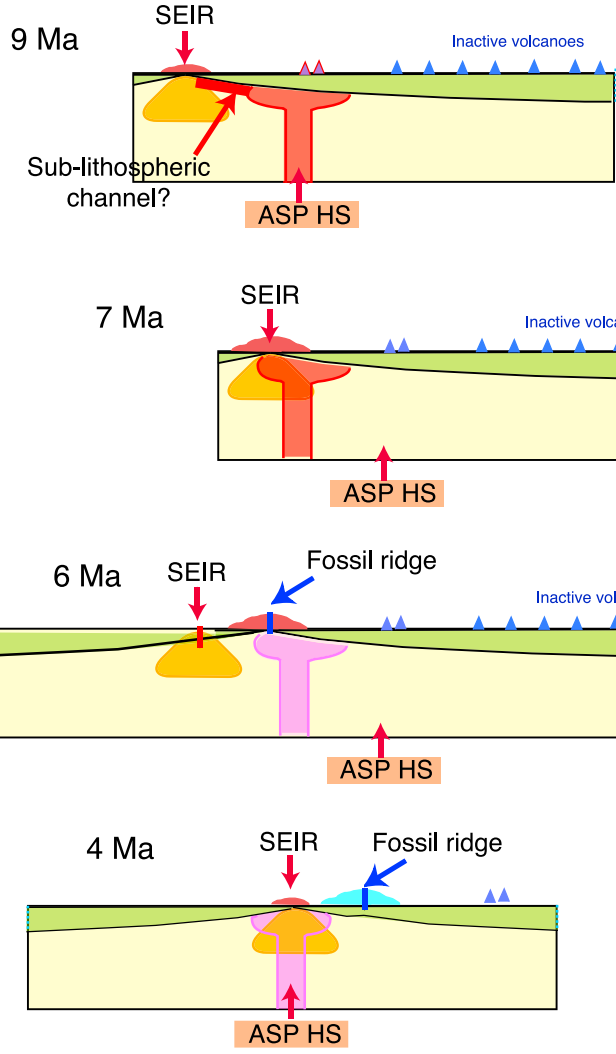

$7 \mathrm{Ma}$

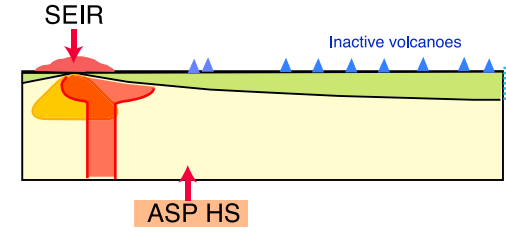

ASP HS

f

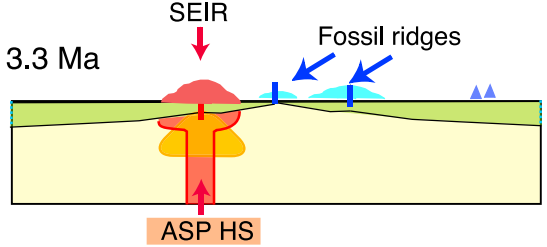

g

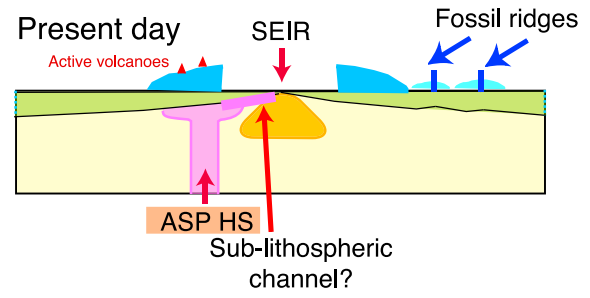

Figure 10. (a-g) Cartoon representing the time evolution of the ridge-hot spot interaction for the ASP (Amsterdam-St. Paul) hot spot and the SEIR (South East Indian Ridge). The different colors of the hot spot represent strong (red) and weak (pink) periods in the source flux. The building of the plateau is represented by the colored domes over the lithosphere, red-brown for active and light blue for old, inactive ones. Same color code for the off-axis volcanoes, represented by small triangles.

of the plateau and by the return to a more tectonic accretion pattern, with newly formed transform discontinuities [Scheirer et al., 2000]. The distance between the SEIR and the ASP hotspot progressively increases, as the ridge continues to migrate to the northeast (Figures 9f and 10g). There is no evidence for recent ridge jumps that would bring the ridge axis closer again to the hotspot center. The increase in the ridge-hotspot distance probably contributes 
to the decrease in the magmatic activity, but it is likely that the ASP hotspot source is again weaker. The establishment of a colder lithosphere at the northern part of the plateau, where volcanism is still active, as suggested by the formation of the small Boomerang transform, strengthens the idea of a present day weaker hotspot source. Temporal variations in hotspot sources (the "plume pulses") have been suggested to explain time variable features in other ridge-hot spot systems, such as Iceland [e.g., Ito, 2001; Smallwood and White, 1998] and the Azores [Cannat et al., 1999; Maia et al., 2007a]. In order to explain the geophysical observations at the ASP-SEIR system, a source of melt, whose strength and position relative to the ridge changed with time, is required. So, although ridge-hot spot relative movement and the ridge spreading rates play a significant part on the process of plateau construction, time variable hot spot source flux (temperature, material or both) during the interaction will contribute to the final structure of the plateau.

\section{Discussion and Conclusions}

[32] Geophysical data presented in this paper and in the companion paper by E. Courrèges et al. (submitted manuscript, 2011) and published geochemical and age data [Graham et al., 1999; Doucet et al., 2004; Nicolaysen et al., 2007; Janin et al., 2009, 2010, 2011] are consistent with the formation of the ASP plateau as resulting from the interaction between the ASP hot spot and the SEIR that provided excess melt resulting in anomalous depths and in excess crust. However, the absence of a long wavelength depth anomaly, expected from a strong and broad thermal effect, as well as the limit of the magmatic activity to a narrow lithospheric compartment, points to a weak hot spot source. Janin et al. [2010, 2011] suggests that the ASP hot spot source is probably a weak plume, although somehow rooted in a larger mantle anomaly.

[33] The ASP plateau formed over a time span of 10 Myr. During this time, a complex interplay of variations in the strength of the hot spot source (or plume) and of ridge-hot spot relative migration resulted in a highly variable ridge structure. Two periods of increased melt supply at the SEIR axis are associated with thick crust and smooth, axial high type morphologies. The two periods are separated by a low magmatic phase, where crust is closer to the world average values and the morphology is of a rift valley type. We interpret the two phases of high melting rates and as being the consequence of periods of high plume flux feeding the ridge axis, provided the hot spot is close enough to the ridge for the connection to be established. The first phase ( 9.7$6.3 \mathrm{Ma}$ ) probably corresponds to an off-axis location of the ASP hot spot. The second and more recent magmatic phase (3.3-0.9 Ma) was associated with higher crustal production, probably because of a coincidence between a strong hot spot source and an on-axis hot spot position. Between 6.3 and 3.3 Ma, the SEIR underwent a low magmatic, more tectonic period. A low plume flux causes the ridge to behave in a more tectonic way, even if the hot spot is located relatively close to the axis. This is observed from 6.3 to $3.3 \mathrm{Ma}$, but also since $0.9 \mathrm{Ma}$, when the hot spot is located west of, but very near the SEIR axis, and the ridge shows a "colder," more tectonic morphology, associated with the breakup of the plateau and the recent development of transform discontinuities.

[34] Temporal variations in plume fluxes with different time periods have been suggested by observations elsewhere. Periods of 10-20 and 5 Myr have been inferred from variations in the volume of volcanism for Hawaii, Tristan da Cunha and St Helen [Vidal and Bonneville, 2004; Adam et al., 2007] and interpreted as linked to oscillations in the plume conduit for the longer period and to solitary waves within the conduit for the shorter ones [Adam et al., 2007]. For the Azores, temporal variations in the plume flux, appearing as short-lived events of larger magmatic production on the ridge axis have been reported [Cannat et al., 1999; Gente et al., 2003; Maia et al., 2007a]. The last pulse built the Jussieu plateau, south of the Azores and an area of thicker crust on the northern part of the Azores 5 Myr ago [Cannat et al., 1999; Maia et al., 2007a]. Crustal thickness variations of $\sim 2 \mathrm{~km}$ and periods of 3 to $6 \mathrm{Myr}$ have been observed in old oceanic crust related to Iceland [Parkin et al., 2007] and at Reykjanes Ridge [Smallwood and White, 1998] and are interpreted as reflecting temporal variations in the Icelandic plume temperature. Numerical models also appeal to plume flux variations to explain the "V" shaped ridges south of Iceland [Ito, 2001]. Thus short period plume pulses may relate to instabilities in the conduit such as solitary waves as suggested by Adam et al. [2007]. Both the amplitude and time span observed in the crust variations related to the Iceland hot spot are coherent with what is observed in the ASP plateau. The 3 Myr oscillations may correspond to variations in the plume flux, as was already suggested by different authors for other hot spots [e.g., Sleep, 1996; Ito, 2001]. The relatively slow ridge-hot spot relative motion together with the intermediate spreading rate of the SEIR favored the early connection between hot spot and ridge and the building of the plateau.

[35] Other possible processes should however be discussed. The plate model [Anderson, 2002] suggests that the locations of melting anomalies are controlled by plate wide stresses and that the presence of fertile, not necessarily hotter, patches in the mantle allow the genesis of large volcanic features, such as Hawaii-Emperor, Louisville or Iceland. Plate stress field and deformation in the presence of fertile/hotter mantle is a good explanation for the more recent magmatic phase of the Dead Poets chain [Janin et al., 2011] but not for the temporal variations in the axial magmatic budget discussed in this paper. It is difficult to explain an increase in the melting rates at the ridge axis by intraplate deformation. Foulger and Anderson [2005] and Foulger [2007] argue that oceanic plateaus form at spreading ridges located above a fertile zone of the upper mantle not necessarily linked to plume heads. Indeed, plateaus are not necessarily connected to plume heads when they form at spreading axes. We showed in this paper that, depending on the ridge spreading rate, even small plumes can create a plateau at a ridge axis. However, in order to explain temporal variations in the crustal thickness at Iceland, Foulger [2007] needs to evoke a temporal variability in the fertility of the source material being tapped by the ridge. Considering the ridge absolute motion and in order to explain our observations, the source for the ASP melts, if their model applies, should be an elongated band of anomalous mantle with highly variable degree of fertility. 
[36] As a general conclusion, the ASP-SEIR system can be seen as resulting from the interaction between a weak hot spot source, probably a small plume, and the lithosphere, where its surface expression would be strongly conditioned by variations in the plume flux, by the presence of a migrating intermediate spreading ridge and by a narrow area of intraplate deformation that allow for intraplate volcanism to occur [Janin et al., 2011]. In this sense, we may be in presence of a "hot line," where the surface expression of the volcanism is mainly controlled by the mechanical characteristics of the overlying lithosphere.

[37] Acknowledgments. The PLURIEL cruise was funded by the Ministère de l'Enseignement Supérieur et de la Recherche through CNRS-INSU and IPEV and by the program EXTRAPLAC. CNRS-INSU through the program SEDIT funded most of the work on the data presented here. We thank Captain F. Duchesne and the crew of RV Marion Dufresne II and the engineers of IPEV for their help with the acquisition of the data during the cruise. Bathymetric data treatment on board was carried on with the help of engineers and technicians of SHOM and IFREMER. We thank to the PLURIEL scientific team for their help with the acquisition and treatment of rock samples and data on board. We are indebted to D. Scheirer for kindly providing us with the data collected during the Boomerang cruise. We thank F. Frey, an anonymous reviewer, and the Associated Editor for comments that improved the quality of this work.

\section{References}

Adam, C., V. Vidal, and J. Escartin (2007), 80-Myr history of buoyancy and volcanic fluxes along the trails of the Walvis and St. Helena hotspots (South Atlantic), Earth Planet. Sci. Lett., 261, 432-442, doi:10.1016/j. eps1.2007.07.005.

Albers, M., and U. Christensen (2001), Channeling of plume flow beneath mid-ocean ridges, Earth Planet. Sci. Lett., 187, 207-220, doi:10.1016/ $\mathrm{S} 0012-821 \mathrm{X}(01) 00276-\mathrm{X}$

Allen, R. M., et al. (2002), Imaging the mantle beneath Iceland using integrated seismological techniques, J. Geophys. Res., 107(B12), 2325, doi:10.1029/2001JB000595.

Anderson, D. (2002), Occam's Razor: Simplicity, complexity and global geodynamics, Proc. Am. Philos. Soc., 146, 56-76.

Behn, M. D., and G. Ito (2008), Magmatic and tectonic extension at midocean ridges: 1. Controls on fault characteristics, Geochem. Geophys. Geosyst., 9, Q08O10, doi:10.1029/2008GC001965.

Blais, A., P. Gente, M. Maia, and D. Naar (2002), A history of the Selkirk paleomicroplate, Tectonophysics, 359, 157-169, doi:10.1016/S00401951(02)00509-7.

Briais, A., D. Aslanian, L. Geli, and H. Ondreas (2002), Analysis of propagators along the Pacific-Antarctic Ridge: Evidence for triggering by kinematic changes, Earth Planet. Sci. Lett., 199, 415-428, doi:10.1016/ S0012-821X(02)00567-8.

Canales, J. P., R. S. Detrick, J. Lin, J. A. Collins, and D. R. Toomey (2000), Crustal and upper mantle seismic structure beneath the rift mountains and across a nontransform offset at the Mid-Atlantic Ridge $\left(35^{\circ} \mathrm{N}\right)$, J. Geophys. Res., 105, 2699-2719, doi:10.1029/1999JB900379.

Canales, J. P., G. Ito, R. S. Detrick and J. Sinton (2002), Crustal thickness along the western Galápagos Spreading Center and the compensation of the Galápagos hotspot swell, Earth Planet. Sci. Lett., 203, 311-327, doi:10.1016/S0012-821X(02)00843-9.

Cande, S., and J. Stock (2004), Pacific-Antarctic-Australia motion and the formation of the Macquarie Plate, Geophys. J. Int., 157, 399-414, doi:10.1111/j.1365-246X.2004.02224.x.

Cannat, M., et al. (1999), Mid-Atlantic Ridge-Azores hot spot interactions: Along-axis migration of a hot spot-derived event of enhanced magmatism 10 to 4 Ma ago, Earth Planet. Sci. Lett., 173, 257-269, doi:10.1016/ S0012-821X(99)00234-4.

Carbotte, S. M., C. Small, and K. Donnelly (2004), The influence of ridge migration on the magmatic segmentation of mid-ocean ridges, Nature, 429, 74-746.

Chen, Y. J. (1996), Constraints on the melt production rate beneath the mid-ocean ridges based on passive flow models, Pure Appl. Geophys., 146, 589-620, doi:10.1007/BF00874735.

Chen, Y. J., and J. Lin (2004), High sensitivity of ocean ridge thermal structure to changes in magma supply: The Galapagos Spreading Center, Earth Planet. Sci. Lett., 221, 263-273, doi:10.1016/S0012-821X(04) 00099-8.
Chen, Y. J., and W. J. Morgan (1990), Rift valley/no rift valley transition at mid-ocean ridges, J. Geophys. Res., 95, 17,571-17,581, doi:10.1029/ JB095iB11p17571.

Cochran, J., J.-C. Sempéré, and SEIR Scientific Team (1997), The Southeast Indian Ridge between $88^{\circ} \mathrm{E}$ and $118^{\circ} \mathrm{E}$ : Gravity anomalies and crustal accretion at intermediate spreading rate, J. Geophys. Res., 102, 15,463-15,487, doi:10.1029/97JB00511.

Conder, J. A., D. S. Scheirer, and D. Forsyth (2000), Seafloor spreading on the Amsterdam-St. Paul hotspot plateau, J. Geophys. Res., 105, 8263-8277, doi:10.1029/1999JB900406.

Doucet, S., D. Weis, J. S. Scoates, V. Debaille, and A. Giret (2004), Geochemical and $\mathrm{Hf}-\mathrm{Pb}-\mathrm{Sr}-\mathrm{Nd}$ isotopic constraints on the origin of the Amsterdam-St. Paul (Indian Ocean) hotspot basalts, Earth Planet. Sci. Lett., 218, 179-195, doi:10.1016/S0012-821X(03)00636-8.

Foulger, G. (2007), The "plate" model for the genesis of melting anomalies, in Plates, Plumes, and Planetary Processes, edited by G. R. Foulger and D. M. Jurdy, Spec. Pap. Geol. Soc. Am., 430, 1-28.

Foulger, G. R., and D. L. Anderson (2005), A cool model for the Iceland hot spot, J. Volcanol. Geotherm. Res., 141, 1-22, doi:10.1016/j.jvolgeores. 2004.10.007.

Frey, F. A., W. B. Jones, H. Davies, and D. Weis (1991), Geochemical and petrologic data for basalts from Sites 756, 757, and 758: Implications for the origin and evolution of Ninetyeast Ridge, Proc. Ocean Drill. Program Sci. Results, 121, 611-659.

Garcia, S., N. Arnaud, J. Angelier, F. Bergerat, and C. Homberg (2003), Rift jump process in northern Iceland since 10 Ma from 40Ar/39Ar geochronology, Earth Planet. Sci. Lett., 214, 529-544, doi:10.1016/S0012821X(03)00400-X.

Gente, P., J. Dyment, M. Maia, and J. Goslin (2003), Interaction between the Mid-Atlantic Ridge and the Azores hot spot during the last $85 \mathrm{Ma}$ : Emplacement and rifting of the hot spot-derived plateaus, Geochem. Geophys. Geosyst., 4(10), 8514, doi:10.1029/2003GC000527.

Graham, D. W., K. T. M Johnson, L. Douglas Priebe, and J. E. Lupton (1999), Hotspot-ridge interaction along the Southeast Indian Ridge near Amsterdam and St. Paul Islands: Helium isotope evidence, Earth Planet. Sci. Lett., 167, 297-310, doi:10.1016/S0012-821X(99)00030-8.

Gripp, A., and R. G. Gordon (2002), Young tracks of hotspots and current plate velocities, Geophys. J. Int., 150, 321-361, doi:10.1046/j.1365246X.2002.01627.x.

Ito, G. (2001), Reykjanes "V"-shaped ridges originating from a pulsing and dehydrating mantle plume, Nature, 411, 681-684, doi:10.1038/ 35079561

Ito, G., and M. D. Behn (2008), Magmatic and tectonic extension at midocean ridges: 2. Origin of axial morphology, Geochem. Geophys. Geosyst. 9, Q09O12, doi:10.1029/2008GC001970.

Ito, G., and J. Lin (1995), Oceanic spreading center-hotspot interactions: Constraints from along-isochron bathymetric and gravity anomalies, Geology, 23, 657-660, doi:10.1130/0091-7613(1995)023<0657: $\mathrm{OSCHIC}>2.3 . \mathrm{CO} ; 2$

Ito, G., J. Lin, and C. W. Gable (1996), Dynamics of mantle flow and melting at a ridge-centered hotspot: Iceland and the Mid-Atlantic Ridge, Earth Planet. Sci. Lett., 144, 53-74, doi:10.1016/0012-821X(96) 00151-3.

Ito, G., J. Lin, and D. Graham (2003), Observational and theoretical studies of the dynamics of mantle plume-mid-ocean ridge interaction, Rev. Geophys., 41(4), 1017, doi:10.1029/2002RG000117.

Janin, M., M. Maia, H. Guillou, C. Hemond, and C. Bollinger (2009), Amsterdam-St. Paul hotspot: Evidence for multiple phases of activity, paper presented at General Assembly, Eur. Geosci. Union, Vienna.

Janin, M., C. Hemond, M. Maia, H. Guillou, P. Nonnotte, and E. Ponzevera (2010), Amsterdam-St Paul Hotspot: Composition, motion and history, paper EGU2010-4522 presented at General Assembly, Eur. Geosci. Union, Vienna.

Janin, M., C. Hémond, H. Guillou, M. Maia, K. T. M. Johnson, C. Bollinger, C. Liorzou, and A. Mudhoklar (2011), Hot spot activity and tectonic settings near Amsterdam-St. Paul plateau (Indian Ocean), J. Geophys. Res., 116, B05206, doi:10.1029/2010JB007800.

Johnson, K. T. M., D. W. Graham, K. H. Rubin, K. Nicolaysen, D. S. Scheirer, E. T. Forsyth, and L. M. Douglas-Priebe (2000), Boomerang Seamount: The active expression of the Amsterdam-St Paul hotspot, Southeast Indian Ridge, Earth Planet. Sci. Lett., 183, 245-259, doi:10.1016/S0012-821X(00)00279-X

Katz, R. F., M. Spiegelman, and S. M. Carbotte (2004), Ridge migration, asthenospheric flow and the origin of magmatic segmentation in the global mid-ocean ridge system, Geophys. Res. Lett., 31, L15605, doi:10.1029/2004GL020388.

Koppers, A., J. P. Morgan, J. W. Morgan, and H. Staudigel (2001), Testing the fixed hotspot hypothesis using 40Ar/39Ar age progressions along 
seamount trails, Earth Planet. Sci. Lett., 185, 237-252, doi:10.1016 S0012-821X(00)00387-3.

Kuo, B.-Y., and D. W. Forsyth (1988), Gravity anomalies of the ridgetransform system in the South Atlantic between 31 and $34.5^{\circ} \mathrm{S}$ : Upwelling centers and variations in crustal thickness, Mar. Geophys. Res., 10, 205-232, doi:10.1007/BF00310065.

Lin, J., G. M. Purdy, H. Schouten, J.-C. Sempere, and C. Zervas (1990), Evidence from gravity data for focused magmatic accretion along the Mid-Atlantic Ridge, Nature, 344, 627-632, doi:10.1038/344627a0.

Ma, Y., and J. Cochran (1996), Transitions in axial morphology along the Southeast Indian Ridge, J. Geophys. Res., 101, 15,849-15,866, doi:10.1029/95JB03038.

Maia, M., and J. Arkani-Hamed (2002), The support mechanism of the young Foundation Seamounts inferred from bathymetry and gravity, Geophys. J. Int., 149, 190-210, doi:10.1046/j.1365-246X.2002.01635.x.

Maia, M., et al. (2000), The Pacific Antarctic Ridge-Foundation hotspot interaction: A case study of a ridge approaching a hotspot, Mar. Geol. 167, 61-84, doi:10.1016/S0025-3227(00)00023-2.

Maia, M., C. Hémond, and P. Gente (2001), Contrasted interactions between plume, upper mantle, and lithosphere: Foundation chain case, Geochem. Geophys. Geosyst., 2(7), 1028, doi:10.1029/2000GC000117.

Maia, M., J. Goslin, and P. Gente (2007a), Evolution of the accretion processes along the Mid-Atlantic Ridge north of the Azores since $5.5 \mathrm{Ma}$ An insight into the interactions between the ridge and the plume, Geochem. Geophys. Geosyst., 8, Q03013, doi:10.1029/2006GC001318.

Maia, M., et al. (2007b), Preliminary report on the PLURIEL cruise, Saint Paul-Amsterdam plateau, Indian Ocean (Mauritius, September 18 - La Réunion, October 31, 2006), InterRidge News, 16, 22-24.

Maia, M., et al. (2008), Evolution of the Saint Paul-Amsterdam Plateau in the last 10 m.y., Eos Trans. $A G U, 89(53)$, Fall Meet. Suppl., Abstract T54B-06.

Mittelstaedt, E., G. Ito, and M. Behn (2008), Mid-ocean ridge jumps associated with hotspot magmatism, Earth Planet. Sci. Lett., 266, 256-270, doi:10.1016/j.epsl.2007.10.055.

Morgan, J. P., and Y. J. Chen (1993), The genesis of oceanic crust: Magma injection, hydrothermal circulation, and crustal flow, J. Geophys. Res., 98, 6283-6297, doi:10.1029/92JB02650.

Morgan, J. P., and D. W. Forsyth (1988), Three-dimensional flow and temperature perturbations due to a transform offset: Effects on oceanic crustal and upper mantle structure, J. Geophys. Res., 93, 2955-2966, doi:10.1029/JB093iB04p02955.

Müeller, R. D., W. R. Roest, J.-Y. Royer, L. M. Gahagan, and J. G. Sclater (1997), Digital isochrons of the world's ocean floor, J. Geophys. Res., 102, 3211-3214.

Nakanishi, M., W. Sager, and A. Klaus (1999), Magnetic lineations within Shatsky Rise, northwest Pacific Ocean: Implications for hot spot-triple junction interaction and oceanic plateau formation, J. Geophys. Res., 104, 7539-7556.

Nicolaysen, K. P., F. A. Frey, J. J. Mahoney, K. T. M. Johnson, and D. W. Graham (2007), Influence of the Amsterdam/St. Paul hot spot along the Southeast Indian Ridge between $77^{\circ}$ and $88^{\circ} \mathrm{E}$ : Correlations of $\mathrm{Sr}, \mathrm{Nd}$, $\mathrm{Pb}$, and $\mathrm{He}$ isotopic variations with ridge segmentation, Geochem. Geophys. Geosyst., 8, Q09007, doi:10.1029/2006GC001540.

Niu, Y., D. Bideau, R. Hekinian, and R. Batiza (2001), Mantle compositional control on the extent of mantle melting, crust production, gravity anomaly, ridge morphology, and ridge segmentation: A case study at the Mid-Atlantic Ridge 33-35 $\mathrm{N}$, Earth Planet. Sci. Lett., 186, 383-399, doi:10.1016/S0012-821X(01)00255-2.

Parkin, C., Z. C. Lunnon, R. S. White, and P. A. F. Christie (2007), Imaging the pulsing Iceland mantle plume through the Eocene, Geology, 35, 93-96, doi:10.1130/G23273A.1.

Parsons, B., and J. G. Sclater (1977), An analysis of the variation of ocean floor bathymetry and heat flow with age, J. Geophys. Res., 82, 803-827, doi:10.1029/JB082i005p00803.

Prince, R. A., and D. W. Forsyth (1988), Horizontal extent of anomalously thin crust near the Vema fracture zone from the three-dimensional analysis of gravity anomalies, J. Geophys. Res., 93, 8051-8063, doi:10.1029/ JB093iB07p08051.

Ribe, N. M., and W. L. Delattre (1998), The dynamics of plume-ridge interaction-III. The effects of ridge migration, Geophys. J. Int., 133, $511-518$.

Rommevaux, C., C. Deplus, P. Patriat, and J. C. Sempéré (1994), Threedimensional gravity study of the Mid-Atlantic Ridge: Evolution of the segmentation between $28^{\circ}$ and $29^{\circ} \mathrm{N}$ during the last $10 \mathrm{~m} . \mathrm{y}, \mathrm{J}$. Geophys. Res., 99, 3015-3029, doi:10.1029/93JB02361.

Royer, J. Y., and R. G. Gordon (1997), The motion and boundary between the Capricorn and Australian plates, Science, 277, 1268-1274, doi:10.1126/ science.277.5330.1268
Sandwell, D. T., and W. H. F. Smith (1997), Marine gravity anomaly from Geosat and ERS 1 satellite altimetry, J. Geophys. Res., 102, 10,039-10,054, doi:10.1029/96JB03223

Schaefer, B., S. Turner, I. Parkinson, N. Rogers, and C. Hawkesworth (2002), Evidence for recycled Archaean oceanic mantle lithosphere in the Azores plume, Nature, 420, 304-307, doi:10.1038/nature01172.

Scheirer, D., D. Forsyth, J. A. Conder, M. A. Eberle, S.-H. Hung, K. T. M. Johnson, and D. W. Graham (2000), Anomalous seafloor spreading of the Southeast Indian Ridge near the Amsterdam-St. Paul plateau, J. Geophys. Res., 105, 8243-8262, doi:10.1029/1999JB900407.

Schilling, J.-G. (1991), Fluxes and excess temperatures of mantle plumes inferred from their interaction with migrating mid-ocean ridges, Nature, 352, 397-403, doi:10.1038/352397a0.

Sempéré, J. C., J. Cochran, and SEIR Scientific Team (1997), The Southeast Indian Ridge between $88^{\circ} \mathrm{E}$ and $118^{\circ} \mathrm{E}$ : Variations in crustal accretion at constant spreading rate, J. Geophys. Res., 102, 15,489-15,505, doi:10.1029/97JB00171.

Shah, A. K., and J.-C. Sempéré (1998), Morphology of the transition from an axial high to a rift valley at the Southeast Indian Ridge and the relation to variations in mantle temperature, J. Geophys. Res., 103, 5203-5223, doi:10.1029/97JB03110.

Sigmarsson, O., and S. Steinthórsson (2007), Origin of Icelandic basalts: A review of their petrology and geochemistry, J. Geodyn., 43, 87-100, doi:10.1016/j.jog.2006.09.016

Sleep, N. (1996), Lateral flow of hot plume material ponded at sublithospheric depths, J. Geophys. Res., 101, 28,065-28,083, doi:10.1029/ 96JB02463.

Sleep, N. (2002), Ridge-crossing mantle plumes and gaps in tracks, Geochem. Geophys. Geosyst., 3(12), 8505, doi:10.1029/2001GC000290.

Small, C. (1995), Observations of ridge-hotspot interactions in the Southern Ocean, J. Geophys. Res., 100, 17,931-17,946, doi:10.1029/95JB01377.

Smallwood, J. R., and R. S. White (1998), Crustal accretion at the Reykjanes Ridge, $61^{\circ}-62^{\circ} \mathrm{N}$, J. Geophys. Res., 103, 5185-5201, doi:10.1029/ 97JB03387.

Smith, W., and D. Sandwell (1997), Global sea floor topography from satellite altimetry and ship depth soundings, Science, 277, 1956-1962, doi:10.1126/science.277.5334.1956.

Stein, C., and S. Stein (1992), A model for the global variation in oceanic depth and heat flow with lithospheric age, Nature, 359, 123-129.

Steinberger, B., and R. J. O'Connell (1998), Advection of plumes in mantle flow: Implications for hotspot motion, mantle viscosity and plume distribution, Geophys. J. Int., 132, 412-434, doi:10.1046/j.1365246x.1998.00447.x.

Thibaud, R., P. Gente, and M. Maia (1998), A systematic analysis of the Mid-Atlantic Ridge morphology and gravity between $15^{\circ} \mathrm{N}$ and $40^{\circ} \mathrm{N}$ : Constraints of the thermal structure, J. Geophys. Res., 103, 223-243.

Torsvik, T. H., R. D. Müller, R. Van der Voo, B. Steinberger, and C. Gaina (2008), Global plate motion frames: Toward a unified model, Rev. Geophys., 46, RG3004, doi:10.1029/2007RG000227.

Vidal, V., and A. Bonneville (2004), Variations of the Hawaiian hot spot activity revealed by variations in the magma production rate, $J$. Geophys. Res., 109, B03104, doi:10.1029/2003JB002559.

Watkins, N. D., I. McDougall, and J. Nougier (1975), Paleomagnetism and potassium-argon age of St. Paul Island, southeastern Indian Ocean: Contrasts in geomagnetic secular variation during the Brunhes Epoch, Earth Planet. Sci. Lett., 24, 377-384, doi:10.1016/0012-821X(75)90144-2.

Weis, D., and F. A. Frey (1991), Isotope geochemistry of Ninetyeast Ridge basalts: $\mathrm{Sr}, \mathrm{Nd}$, and $\mathrm{Pb}$ evidence for the involve involvement of the Kerguelen hot spot, in Proc. Ocean Drill. Program Sci. Results, 121, 591-610.

Wessel, P., and W. H. F. Smith (1998), New improved version of Generic Mapping Tools released, Eos Trans. $A G U, 79(47), 579$.

E. Courrèges, M. Patriat, and W. Roest, IFREMER, Département de Géosciences Marines, Centre de Brest, F-29280 Plouzané, France.

P. Gente, C. Hémond, M. Maia, and J.-Y. Royer, Laboratoire Domaines Océaniques, Institut Universitaire Europeen de la Mer, Université de Brest, CNRS, Rue Dumont d'Urville, Plouzané F-29280, France. (Marcia.Maia@ univ-brest.fr)

M. Janin, Commissariat à l'Énergie Atomique, F-91191 Gif-sur-Yvette, France.

K. Johnson, Department of Geology and Geophysics, School of Ocean and Earth Sciences and Technology, University of Hawaii at Manoa 1680 East-West Rd., POST 606B, Honolulu, HI 96822, USA.

I. Pessanha, LAGEMAR, Universidade Federal Fluminense, Av. Litorânea S/N, Niterói, Brazil.

J. Vatteville, Laboratoire de Dynamique des Fluides Géologiques, Institut de Physique du Globe, Tour 14, Aile 14-15, 1er étage, 4 Place Jussieu, F-75252 Paris, France. 